\title{
Hypertensive disorders in pregnancy: Assessing postnatal quality of care and outcomes for women and their infants in Bangladesh
}

\author{
Sharif M.I. Hossain \\ Population Council \\ Kanij Sultana \\ Population Council \\ Salma Rouf \\ Rabeya Akter \\ Shongkour Roy \\ Population Council
}

See next page for additional authors

Follow this and additional works at: https://knowledgecommons.popcouncil.org/departments_sbsr-rh

Part of the Demography, Population, and Ecology Commons, Family, Life Course, and Society Commons, Gender and Sexuality Commons, International Public Health Commons, Maternal and Child Health Commons, Medicine and Health Commons, and the Women's Health Commons How does access to this work benefit you? Let us know!

\section{Recommended Citation}

Hossain, Sharif M.I., Kanij Sultana, Salma Rouf, Rabeya Akter, Shongkour Roy, Sumaiya Anwar, Karen Kirk, and Charlotte E. Warren. 2019. "Hypertensive disorders in pregnancy: Assessing postnatal quality of care and outcomes for women and their infants in Bangladesh," Ending Eclampsia HDP postnatal follow up report. Washington, DC: Population Council. 


\section{Authors}

Sharif M.I. Hossain, Kanij Sultana, Salma Rouf, Rabeya Akter, Shongkour Roy, Sumaiya Anwar, Karen Kirk, and Charlotte E. Warren 


\section{ENDING Eclampsia}

\section{Hypertensive Disorders} in Pregnancy: Assessing Postnatal Quality of Care and Outcomes for Women and Their Infants in Bangladesh

Sharif Hossain

Kanij Sultana

Salma Rouf

Rabeya Akter Shongkour Roy Sumaiya Anwar

Karen Kirk Charlotte Warren 


\section{Eclampsia}

Ending Eclampsia seeks to expand access to proven, under-utilized interventions and commodities for the prevention, early detection, and treatment of pre-eclampsia and eclampsia and strengthen global partnerships.

\section{POPULATION COUNCIL \\ Ideas. Evidence. Impact.}

The Population Council confronts critical health and development issues-from stopping the spread of HIV to improving reproductive health and ensuring that young people lead full and productive lives. Through biomedical, social science, and public health research in 50 countries, we work with our partners to deliver solutions that lead to more effective policies, programs, and technologies that improve lives around the world. Established in 1952 and headquartered in New York, the Council is a nongovernmental, non-profit organization governed by an international board of trustees.

\section{Population Council}

4301 Connecticut Avenue NW, Suite 280

Washington, DC, 20008

Tel: +1. 877.237.9400

www.popcouncil.org

Population Council

House 12, Road 25/30

Gulshan 1, Dhaka 1212

Bangladesh

Tel: +8802 9842276, 9846657

email: info.bangladesh@popcouncil.org

The Ending Eclampsia project is made possible by the generous support of the American people through the United States Agency for International Development (USAID) under the terms of USAID APS-OAA-14000048. The contents of this report are the sole responsibility of the Ending Eclampsia project and the Population Council and do not necessarily reflect the views of USAID or the United States Government. 


\section{Table of Contents}

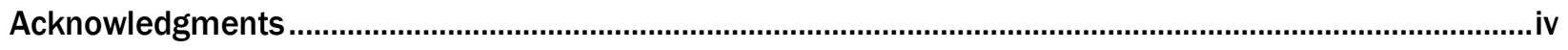

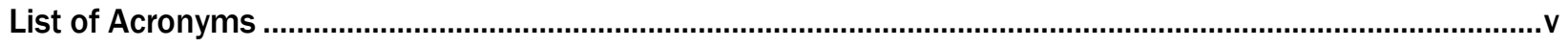

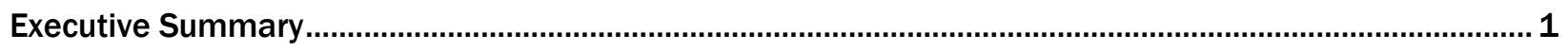

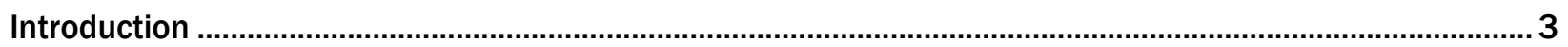

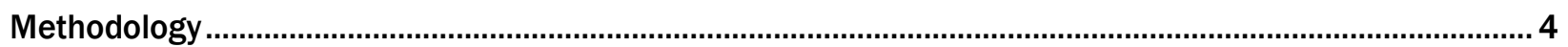

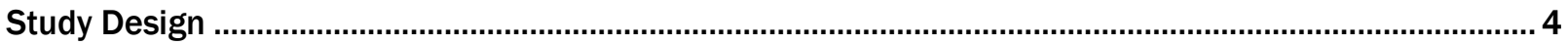

Study Setting

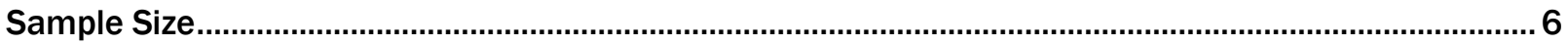

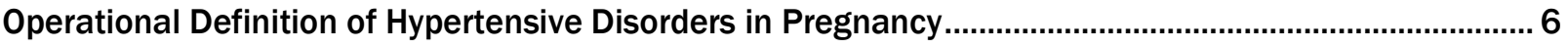

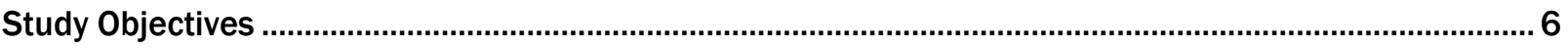

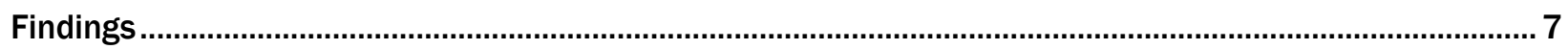

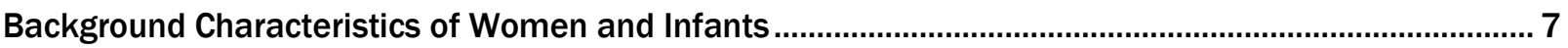

Quality of Care for Women and Their Infants During the Postnatal Period ............................................13

Women's Perceptions and Experiences with Hypertensive Disorders in Pregnancy and Their Care......16

Clinical Courses of Women with Hypertensive Disorders in Pregnancy .....................................................16

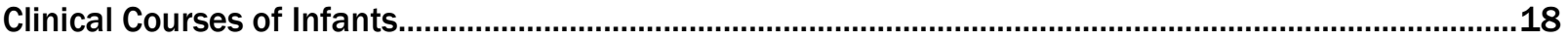

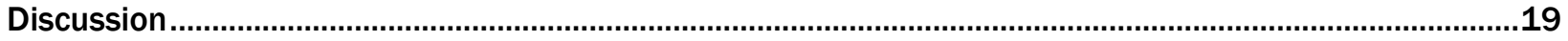

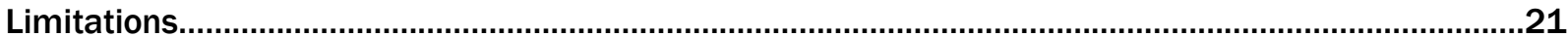

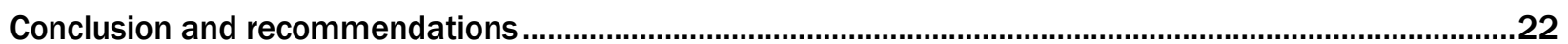

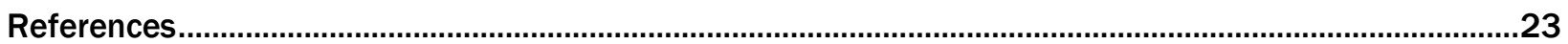

Appendix: Clinical and Laboratory Parameters Assessed......................................................................26 


\section{Acknowledgments}

This report is based upon postnatal follow up with women to determine gaps in standards of care for women in Bangladesh with hypertensive disorders in pregnancy, and to assess any pattern of morbidities among those women and their infants within one year of delivery. This study is part of the Ending Eclampsia project, conducted in collaboration with the Gynecology and Obstetrical Department of Dhaka Medical College and Hospital of Bangladesh.

We are thankful to the United States Agency for International Development (USAID) for their technical and financial support, and for providing valuable suggestions for the design and necessary guidance to complete research. Particular thanks to Ms. Emily Hillman, Dr. Samina Choudhury, and Ms. Edna Jonas for their continuous guidance and intelligence for completion of this study.

We would like to express our sincere thanks and gratitude to Professor Dr. Ismail Khan, former principal of Dhaka Medical College and Dean of Faculty of Medicine of Dhaka University, and current Vice Chancellor of Chittagong Medical University, for his support and contributions during the ethical approval process at Dhaka Medical College and Hospital. We would also like to acknowledge Professor Salma Rouf for providing logistical support during the study at Dhaka Medical College and Hospital.

We further acknowledge the support and assistance of doctors and nurses of the Eclampsia Unit of the Department of Gynecology and Obstetrics at Dhaka Medical College and Hospital. We are indebted to Professor Nazmul Islam Munna, Director of Medical Education and Health Manpower Development, and all the laboratory departments of Dhaka Medical College and Hospital for their support during the implementation of this study.

It is our pleasure to acknowledge Ms. Sumaiya Binte Anwar, Research Assistant for this study, for her tremendous efforts in client follow up, accompanying clients for laboratory investigations, and data entry.

We are indebted and respectful to those mothers who gave their time and patience in providing interviews and invaluable information, as well as making their children and themselves available for follow up, including physician and laboratory examinations. Without their cooperation, the study would not have been possible.

Finally, we appreciate our colleagues at the Population Council whose efforts in training, data collection and analysis, and administrative support have made these results possible. 


\section{List of Abbreviations}

\begin{tabular}{|c|c|}
\hline ANC & Antenatal Care \\
\hline BP & Blood Pressure \\
\hline dL & Deciliter \\
\hline $\mathrm{DMCH}$ & Dhaka Medical College and Hospital \\
\hline EO-PE & Early Onset Pre-Eclampsia \\
\hline FP & Family Planning \\
\hline HDL & High Density Lipoprotein \\
\hline HDP & Hypertensive Disorder in Pregnancy \\
\hline HTN & Hypertension \\
\hline Kg & Kilogram \\
\hline LBW & Low Birth Weight \\
\hline LDL & Low Density Lipoprotein \\
\hline LO-PE & Late Onset Pre-Eclampsia \\
\hline Mg & Milligram \\
\hline $\mathrm{mmHg}$ & Millimeters of Mercury \\
\hline NICE & National Institute for Clinical Excellence \\
\hline Ob/Gyn & Obstetrics and Gynecology \\
\hline PE & Pre-Eclampsia \\
\hline $\mathrm{PE} / \mathrm{E}$ & Pre-Eclampsia and Eclampsia \\
\hline PNC & Postnatal Care \\
\hline RCOG & Royal College of Obstetricians and Gynecologists \\
\hline $\mathrm{U} / \mathrm{L}$ & Units per Liter \\
\hline UK & United Kingdom \\
\hline USAID & United States Agency for International Development \\
\hline WHO & World Health Organization \\
\hline
\end{tabular}




\section{Executive Summary}

Hypertensive disorders in pregnancy (HDPs) (BP $\geq 140 \mathrm{mmHg} / \geq 90 \mathrm{mmHg}$ ) are the second leading cause of maternal mortality in Bangladesh, responsible for 24 percent of maternal deaths. Various factors, such as lack of health care provider capacities for detecting, preventing, and managing pre-eclampsia and eclampsia (PE/E), late referrals, late (or lack of) antenatal care (ANC), and poor awareness of PE/E, are factors in most of these avoidable deaths. While some information was available on the prenatal and postnatal periods, there was an evidence gap in information after delivery through the first year postnatal, and beyond.

For most women with HDP in Bangladesh, care largely stops after delivery, yet studies suggest that complications associated with HDP continue throughout the immediate postnatal period and longer. While standard international guidelines recommend lifelong care and monitoring, at a minimum close monitoring for at least six months to one year after delivery is recommended. In this prospective cohort study, the Ending Eclampsia project recruited married women ages 15 to 49 years (after their informed consent) with HDP, along with their infants, around the time of delivery and prospectively followed them for up to one year to evaluate their care, assess their health statuses, and identify any pattern of morbidities through record reviews, interviews, medical checks and laboratory tests.

This study was conducted in the Eclampsia Unit of a tertiary care hospital in Dhaka. All clients admitted to the study in its first six months were enrolled for a record review, and consenting women were enrolled for follow up at their ninth week, sixth month, and $12^{\text {th }}$ month postnatal. A trained Research Assistant with the help of nurses, midwives, or medical officers in the Obstetrics and Gynecology Department recruited study participants, reviewed their treatment records, and conducted a survey guided by a standardized questionnaire. Medical check ups of women and their infants were conducted by an obstetrician and a pediatrician, respectively, and laboratory tests were performed in a private reference laboratory.

Among the 400 women with HDP enrolled for record reviews, 160 women consented to follow up, as estimated for the study. The number of women with HDPs who returned at their ninth week, sixth month, and $12^{\text {th }}$ month following enrollment were 48 (30.0\%), 26 (16.3\%), and 32 (20.0\%), respectively. For all record reviews, two fifths of women were under age 25, and more than 90 percent had some primary or further education, two fifths were primigravida (i.e. pregnant for the first time), and three quarters were admitted to the Eclampsia Unit at 34 or more weeks' gestation. About 60 percent of infants weighed less than 2.5 kilograms (kg) at birth. The overall rate of early onset PE (at <34 weeks gestation) was 25.3 percent, with no significant variations within the four HDP sub-types (chronic hypertension (HTN), gestational HTN, PE, eclampsia). The rate of pre-term delivery was extremely high, at 62.5 percent, with gross variations by HDP sub-type. The stillbirth rate was 15.3 percent, which also varied by HDP sub-type.

Poor quality of care and poor documentation were evident. For example, while blood pressure (BP) was measured for 89 percent of the women on their first day postnatal, and documented, by the fifth day only 14 percent of women had BP measured and documented. While all women with HDPs should continue antihypertensive medication until their BP is well-controlled, about 30 percent of women who had PE with BP $\geq 150 / 100 \mathrm{mmHg}$ were on no anti-hypertensive drugs during their first week postnatal. Women whose data were available from all four data collection points $(n=21)$ reveal that a number of them remained hypertensive one year postnatal. Similarly, while nephrological evaluation requires attention equal to BP measurement, there was limited documentation, and evaluation progressively declined from the first through the fifth day. Findings show that 10.5 percent of women with HDP had significant albumin in their urine on the day of discharge. 
Almost all women who remained hypertensive were offered medical reviews at two weeks postpartum, and at six to eight weeks after discharge, however, documented in the record reviews. Record reviews also show that not all women were documented or evaluated for metabolic functions, though. Women observed and tested for metabolic functions over a year showed considerable metabolic disfunctions since delivery: 6.3 percent of those women had persistent high creatinine levels, 12.5 percent had elevated aspirate transferase, 34.4 percent had elevated alanine transferase, and many had dyslipidemia.

The following conclusions and recommendations emerged from this study, to help health care providers, public health experts, policy decision-makers, health administrators, and developmental partners in Bangladesh provide better services to women with HDPs:

- Gaps in PNC are evident including clinical assessment, laboratory evaluations, follow up, and counseling. Standard operating procedures (SOPS) for PNC should be developed, including management of women with HDPs, and made widely available to obstetricians, nurses, and midwives who provide services to pregnant women.

- Health care challenges need to be addressed in the postnatal period. Women with pregnancy and postnatal complications, and their families, require specific, relevant information to enable their awareness and understanding of their potential consequences to their future health, and why they should attend follow up consultations. Women with pregnancy and postnatal complications are barely counseled about their potential effects on their future health, however. Health care facilities must find ways to ensure women return for follow up care, and increase efficiencies so service providers can provide effective counseling.

- Blood pressure is either not routinely measured, or measured but not documented. Service providers who treat pregnant women should be aware of the importance of routine BP measurement, and continued monitoring in women after delivery, and its documentation. This continuous monitoring applies to urine albumin as well.

- Service providers should all know that hypertension in women with HDP does not necessarily resolve after delivery. They must monitor all women with HDP until documented resolution of the hypertension, to avoid any further complications. Screening for development of metabolic syndromes after PEcomplicated pregnancies should be routine by service providers.

- Early detection of HDP and careful management is essential: All pregnant women should be screened for PE after 20 weeks of pregnancy.

- Pre-term delivery and low birth weight (LBW) infants were extremely common in this study. All women with HDP should be made aware of the necessity of hospital delivery with neonatal support.

- Women who experienced HDPs were rushed or referred to Dhaka Medical College and Hospital from a number of districts surrounding Dhaka, which indicates inefficiencies or lack of capacity at lower levels to manage such cases, which demands improvements in other districts' and facilities' capacities. 


\section{Introduction}

Hypertensive disorders in pregnancy (HDP) are responsible for 70,000 maternal deaths globally, killing one woman every 11 minutes (Magee et al 2016). HDP is the second leading cause of maternal mortality in Bangladesh, according to the Bangladesh Maternal Mortality Survey 2017, with about 24 percent of the country's maternal deaths caused by pre-eclampsia/eclampsia (PE/E) (Niport et al 2018), which affects women during pregnancy, childbirth, as well as postpartum. Factors such as lack of health care provider capacities to detect, prevent, and manage PE/E, late referrals of HDP clients, late attendance and lack of antenatal care (ANC) and awareness about PE/E among communities have been implicated as reasons for most of these avoidable deaths (Warren et al 2015).

Ending Eclampsia baseline analyses of 12 Bangladesh sub-districts' health care facilities' readiness and providers' competencies for detecting and managing HDP revealed gaps in care for women with HDP during the antenatal period (Warren et al 2015). One critical gap was information provided after childbirth, in the immediate postpartum period and thereafter. The United Kingdom's National Institute for Clinical Excellence (NICE) guideline recommends frequent blood pressure (BP) measurement in the days after delivery, as peak BP occurs three to five days following delivery. Women who had gestational hypertension or PE should receive a comprehensive medical review six to eight weeks after delivery, with a discussion of their increased lifetime cardiovascular risk, anti-hypertensive treatment, and risk for future pregnancy (NICE 2013, RCOG 2010). The NICE guideline also recommends stopping methyldopa within two days of delivery, as the drug has been associated with depression, which may exacerbate risk of postpartum depression (NICE 2013, Beilin et al 1977). In addition, some women with HDP who required no anti-hypertensive treatment during pregnancy may require it postnatally, and, in fact, about 45 percent of eclampsia occurs in the immediate postnatal period, mostly within the first four days, but may occur up to four weeks later, so meticulous BP surveillance after delivery is highly recommended (RCOG 2010, Firoz and Melnik 2011, NICE 2013).

It has also been documented that about 25 percent of women with HDP, especially those with a severe condition, experience a deterioration of end-organ functions during puerperium (the 6 to 8 weeks after delivery, during which pregnancy changes return to baseline) (Deruelle et al 2006). PE early in pregnancy ( $<34$ weeks of gestation), presenting in a severe form, or persistence of proteinuria more than three to six months after delivery suggests possible chronic hypertension or renal disease. Women with PE are also at increased risk for venous thromboembolism in the postnatal period, and those women should receive thromboembolic prophylaxis after delivery until they are fully mobile, usually within four to six weeks (RCOG 2015). Similarly, women with pre-term PE and gestational hypertension have been found to develop persistent cardiovascular impairment one year after delivery (Melchiorre et al 2011), including other chronic diseases such as chronic hypertension, stroke, renal disease, diabetes mellitus, and ischemic heart disease. Infants born to women with HDP also require special attention in the immediate postnatal period due to a combination of short- and long term risks. Standard international guidelines recommend lifelong care and monitoring, or a minimum of care and monitoring for six months to one year after delivery. Studies suggest that complications associated with HDP continue in the immediate postnatal period and longer (NICE 2011).

Currently there is no locally available guideline in Bangladesh that directs postnatal care (PNC) for women with HDP, and even WHO's PE prevention and management guideline does not include the postnatal period. Nothing much is known of the kind and contents of care (if any at all) women with HDP receive, and of associated morbidities after delivery in Bangladesh. It is assumed that care for women with HDP in Bangladesh largely stops after delivery. 
In this prognostic study, the Ending Eclampsia project recruited women ages 15 to 49 years with HDP, following their informed consent, as well as their infants, around the time of their deliveries, and prospectively followed them for up to one year, to evaluate their care, assess their health statuses, and identify any morbidity patterns. This gap analysis not only provides insights into the quality of care women with HDP received postnatally, as well as their health statuses and morbidity patterns, including their infants, but will improve policy-makers' and program managers' understanding of actual patient care and inform the design of interventions to improve the future care of women with HDPs.

\section{Methodology}

\section{Study Design}

This was a prospective cohort study of one year involving married pregnant women 15 to 49 years of age diagnosed with HDPs, and included their infants, who attended a tertiary care hospital in Bangladesh-the Eclampsia Unit of Dhaka Medical College and Hospital (DMCH). The study has no comparison group. A woman with any diagnosed HDP (chronic hypertension, gestational hypertension, PE/E) who was admitted to the eclampsia unit of DMCH's Ob/Gyn Department for complications management near the time of her delivery was eligible to be a study participant.

Women suffering from HDPs were selected for participation on a volunteer basis, with the selection criteria of: any married woman age 15 to 49 with any HDP admitted to the eclampsia unit willing to provide her informed consent. After informing each woman with HDP of the study's purpose and its objectives, women willing to participate in the study were asked for their written informed consent, for current and subsequent interviews, standard medical examinations and laboratory tests (see Appendix), and subsequent interviews. Those willing to participate were enrolled, their records were reviewed, and medical examinations and laboratory tests were conducted, following a baseline interview. HDP participants were enrolled over a period of six months. A trained Research Assistant, with the help of nurses, midwives, or medical officers in the department, recruited study participants, reviewed their treatment records, and conducted a survey prescribed by a standardized questionnaire. Standard medical examinations of women and their infants were by an obstetrician and a pediatrician, respectively.

All eligible pregnant women with HDPs admitted to the eclampsia unit during the enrollment period were selected for record reviews. Only those who provided informed consent to participate in the study were selected for subsequent follow up, including routine physical and medical examinations, laboratory tests, and an interview dictated by a standardized questionnaire. Physical examinations and clinical information for the infants of enrolled women were also conducted at baseline and at subsequent visits. Women and their infants were assessed prospectively at nine weeks, six months, and one year, when the clinical and laboratory assessments conducted at baseline were repeated.

This study gathered information on the content and quality of care these women received for one year postnatal through individual interviews during each follow up visit.

The study commenced in November 2017, and the last client to be enrolled exited the study on June 30, 2019. To improve the follow up rate, women were encouraged (if they wished) to provide their mobile phone numbers (and their partners') for ease of follow up at the designated time period. 


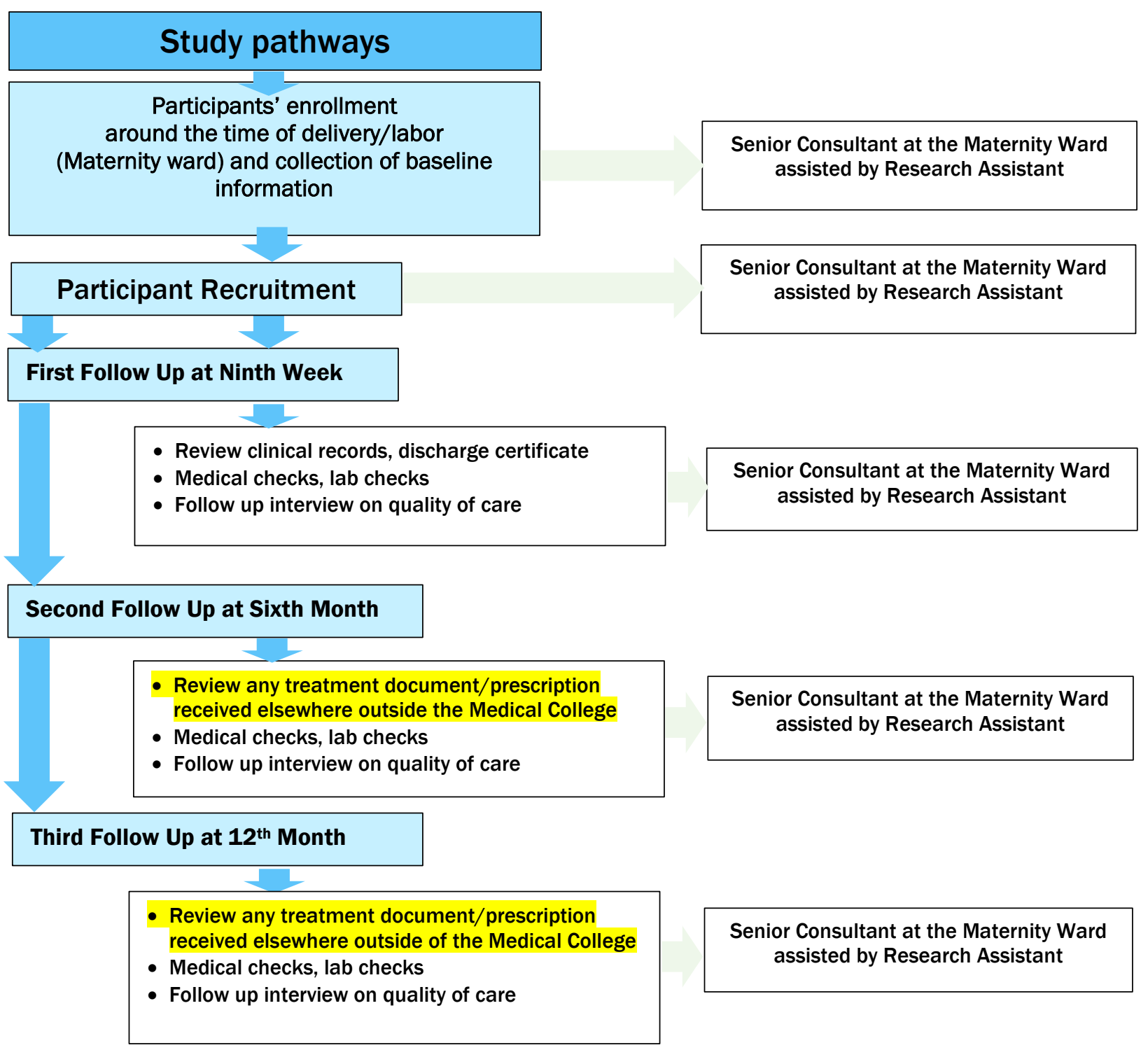

\section{Study Setting}

The study was conducted in the maternity and eclampsia units of Dhaka Medical College and Hospital $(\mathrm{DMCH})$. This tertiary facility is a high volume site with well-functioning ANC clinics, delivery rooms, PNC clinics, but with a weak data management system. This facility not only serves women in and around Dhaka district, but from other parts of the country. We collaborated closely with DMCH's Obstetrical and Gynecological (Ob/Gyn) department to recruit and follow enrolled participants. Challenges prevented the hospital laboratory from performing all required investigations, so laboratory tests were instead performed at a reputable private facility. 


\section{Sample Size}

The study was designed to recruit and follow as many women as possible within a six month enrollment period. Given a 10 percent of incidence of HDP, with 95 percent confidence interval and five percent precision, it was estimated that 138 women were required for participation in this study. Considering a potential 20 percent non-response rate, 166 women were needed for statistical analysis. Ultimately 160 women with HDP (and their infants) were recruited for the study, to be followed for one year, with their full informed consent. Record reviews were conducted with all 400 women with HDP admitted to the eclampsia unit during the six month enrollment period.

\section{Operational Definition of Hypertensive Disorders in Pregnancy}

HDP refers to a group of medical conditions in pregnancy characterized by the presence of high blood pressure (BP $\geq 140 / \geq 90 \mathrm{mmHg}$ ). A woman was considered hypertensive if her index pregnancy was complicated by any of the following hypertensive conditions:

- Chronic hypertension in pregnancy, which is any hypertension ( $\mathrm{BP} \geq 140 / \geq 90 \mathrm{mmHg}$ ) present before pregnancy or diagnosed before 20 weeks' gestation;

- Gestational hypertension, any hypertension (BP $\geq 140 / \geq 90 \mathrm{mmHg}$ ) appearing for the first time after the $20^{\text {th }}$ week of pregnancy;

- Pre-eclampsia and eclampsia, which are any hypertension ( $\mathrm{BP} \geq 140 / \geq 90 \mathrm{mmHg}$ ) appearing for the first time after 20 weeks of pregnancy and associated with significant protein in urine; if a client with $\mathrm{PE}$ develops convulsion in the absence of any neurological cause, it is seen as eclampsia; and

- Significant protein in urine (proteinuria), with protein excretion in urine of $\geq 2++$, measured using urine dipsticks.

\section{Study Objectives}

The overall goal of this study is to identify service delivery gaps and patterns of morbidities associated with HDP within one year postnatal. The project's learning objectives and research questions are:

- What care do women with HDPs typically receive (clinical and biochemically), following delivery (immediately postpartum and extended postpartum period of up to one year) compared to international guidelines, as benchmarks?

- What care do infants of women with HDP typically receive following delivery (immediately postpartum and extended postpartum period up to one year), compared to international guidelines, as benchmarks?

- What are the experiences, expectations, and satisfaction with services of women with HDPs during and after their pregnancies? 


\section{Findings}

\section{Background Characteristics of Women and Infants}

Four hundred women with HDP, both in or near delivery, were admitted to DMCH's eclampsia unit from November 2017 to April 2018. These 400 women's, and their infants', baseline clinical and laboratory information were reviewed, through record reviews, after receiving informed consent from the women. Among these 400 women with HDP, 160 consented to participate in follow up activities, and the proportion of women who returned at nine weeks, six months, and one year were 30.0 percent, 16.3 percent, and 20.0 percent, respectively. The proportions of infants brought at nine weeks, six months, and one year for check ups were lower principally due to neonatal deaths, while some were not brought in because of sickness on the date of follow up (Table 1).

Table 1: Distribution of postnatal women with Hypertensive Disorders in Pregnancy and their infants

\begin{tabular}{|l|c|c|}
\hline Type of data & Women (n) & Infants (n) \\
\hline Women and infant records reviewed, baseline data collected & 400 & 400 \\
\hline Women consented to be followed up & 160 \\
\hline Women and infants showed up at 9 weeks & $48(30.0 \%)$ & $35(21.8 \%)$ \\
\hline Women and infants showed up at 6 months & $26(16.3 \%)$ & $17(10.6 \%)$ \\
\hline Women and infants showed up at 12 months & $32(20 \%)$ & $25(15.6 \%)$ \\
\hline
\end{tabular}

While most women were from Dhaka district, women from other parts of the country also sought emergency services at the hospital or were referred from other districts. The women came from 28 districts total, while 47 percent were from Dhaka district.

Figure 1: Distribution of women with Hypertensive Disorders in Pregnancy admitted, by residence

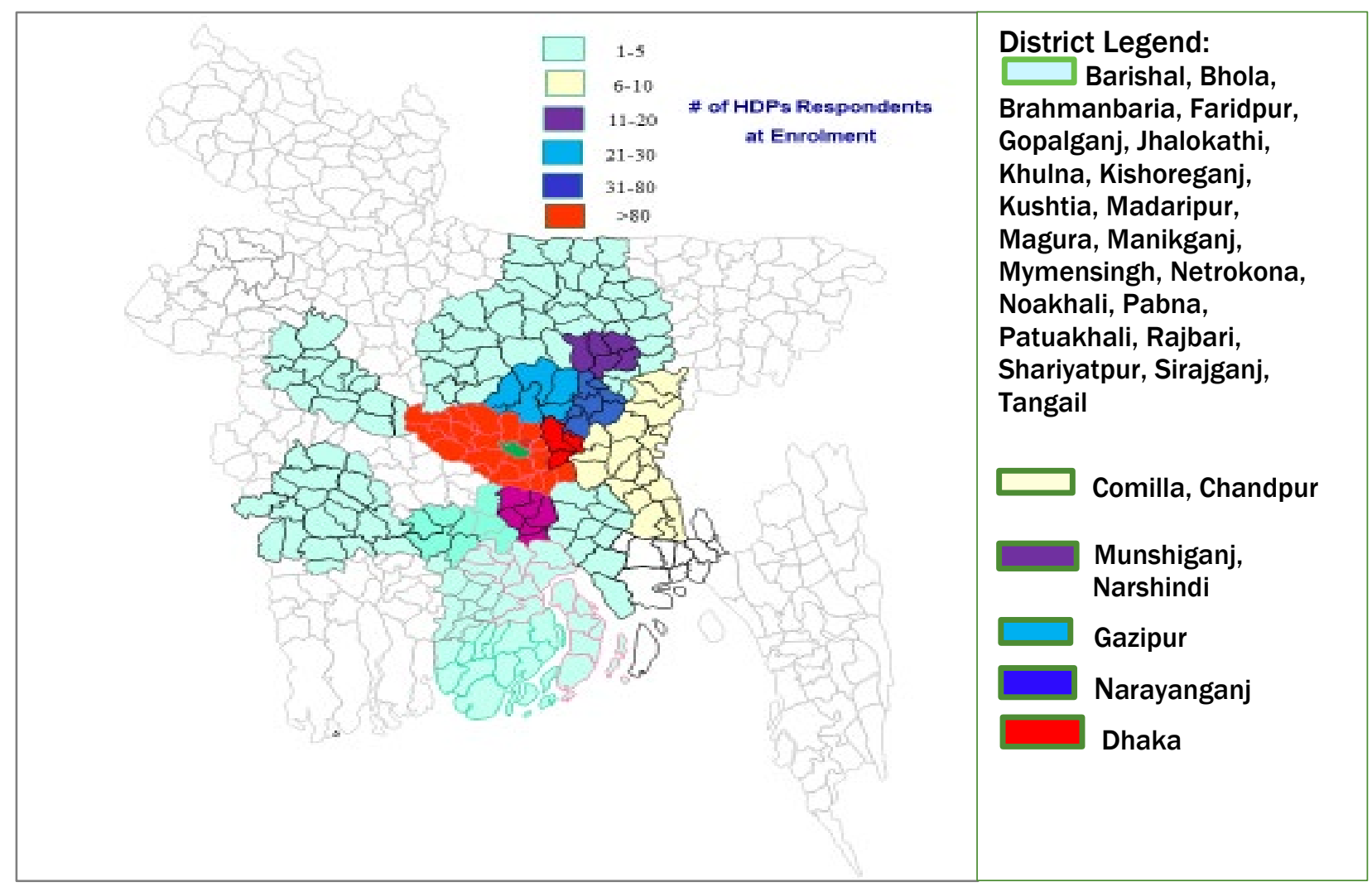


Table 2 describes the socio-economic characteristics and birth outcomes of the 400 HDP enrolled women, with two fifths of the women under age 25, more than 90 percent with at some primary or further education, two fifths primigravida, and three quarters admitted to the Eclampsia Unit at 34 or more weeks of gestation. About 60 percent of infants had birth weight of less than $2.5 \mathrm{~kg}$.

Table 2: Demographic and medical characteristics of women and infants (record review)

\begin{tabular}{|c|c|c|}
\hline Characteristic & Number $(n=400)$ & Percentage (\%) \\
\hline \multicolumn{3}{|l|}{ Women's ages at baseline (year) } \\
\hline$<20$ & 53 & 13.3 \\
\hline $20-24$ & 105 & 26.3 \\
\hline $25-29$ & 121 & 30.2 \\
\hline $30-34$ & 77 & 19.2 \\
\hline$>34$ & 44 & 11.0 \\
\hline Median age & \multicolumn{2}{|c|}{25 years } \\
\hline \multicolumn{3}{|l|}{ Education } \\
\hline No education & 37 & 9.2 \\
\hline Primary & 173 & 43.2 \\
\hline Secondary & 151 & 37.8 \\
\hline Higher secondary and above & 39 & 9.8 \\
\hline \multicolumn{3}{|l|}{ Parity } \\
\hline Prime & 161 & 40.3 \\
\hline $2-3$ & 188 & 47.0 \\
\hline$\geq 4$ & 51 & 12.7 \\
\hline \multicolumn{3}{|l|}{ Gestational age at enrolment (weeks) } \\
\hline$<34$ & 101 & 25.3 \\
\hline$\geq 34$ & 287 & 71.8 \\
\hline Admitted in PNC & 12 & 3.0 \\
\hline \multicolumn{3}{|l|}{ Systolic BP at baseline $(\mathrm{mmHg})$} \\
\hline$<140$ & 65 & 16.3 \\
\hline $140-159$ & 117 & 29.3 \\
\hline$\geq 160$ & 218 & 54.5 \\
\hline \multicolumn{3}{|l|}{ Diastolic BP at baseline ( $\mathrm{mmHg})$} \\
\hline$<90$ & 32 & 8.0 \\
\hline 90-109 & 195 & 48.8 \\
\hline$\geq 110$ & 173 & 43.2 \\
\hline \multicolumn{3}{|l|}{ Urine proteinuria } \\
\hline Nil & 73 & 18.2 \\
\hline Trace & 49 & 12.2 \\
\hline $1+$ & 40 & 10.0 \\
\hline $2+$ & 59 & 14.8 \\
\hline $3+$ & 66 & 16.5 \\
\hline 4+ & 113 & 28.3 \\
\hline Birth weight (kg) & $(n=325)^{1}$ & \\
\hline$<2.5$ & 191 & 58.8 \\
\hline $2.5-3.5$ & 119 & 36.6 \\
\hline$>3.5$ & 15 & 4.6 \\
\hline \multicolumn{3}{|l|}{ Birth outcome } \\
\hline Alive & 325 & 81.2 \\
\hline Stillbirth & 61 & 15.3 \\
\hline Early newborn death ( $<7$ days postnatal) & 14 & 3.5 \\
\hline
\end{tabular}

175 infants' weight were missing in the records and were not included in this analysis 
Figure 2 shows that most women with HDP admitted to the hospital during labor and delivery had severe PE/E (66.7\%), 22 percent experienced PE, nine percent had gestational hypertension, and the rest (3\%) had chronic hypertension.

Figure 2: Types of Hypertensive Disorder in Pregnancy at admission $(n=400)$

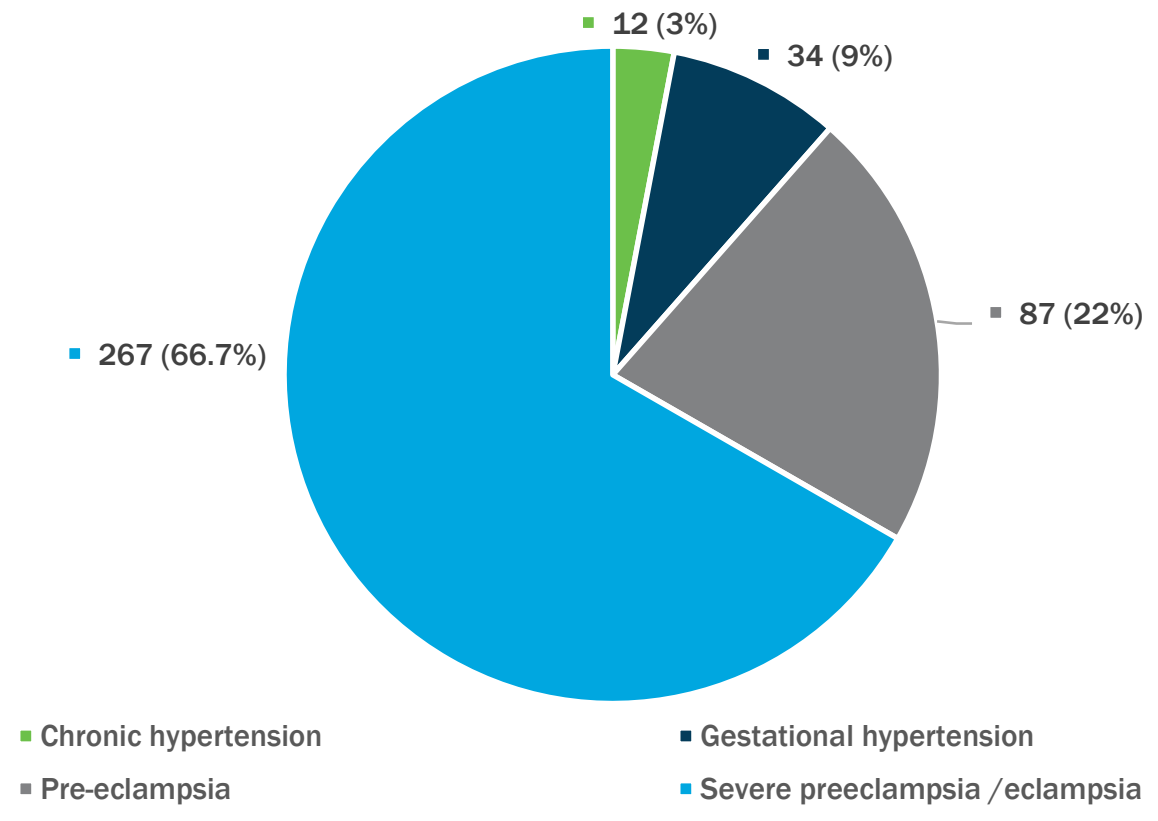

"Preeclampsia is a heterogeneous disorder, progress in the understanding of this disorder would be assisted greatly if subtypes could be characterized. It is recommended to subdivide preeclampsia into earlyonset (EO-PE) disease (occurring at $<34$ weeks gestation) and late onset (LO-PE) disease (occurring at $<34$ weeks gestation)" (Dadelszen et al 2003).

Of the total 400 women with HDPs whose records were reviewed in this study, the overall EO-PE disease rate reported was 25.3 percent, with no significant variations among the four HDP sub-types. Of the total 354 women with sub-type PE/E, 25.7 percent reported EO-PE, while the remaining 74.3 percent reported LO-PE. For HDP sub-type gestational hypertension, only 20.6 percent of women reported EO-PE, while 25 percent of women reported of HDP sub-type chronic hypertension (Table 3, following page).

Gestational age at birth is associated with pre-term delivery, growth restriction, LBW, stillbirth, and some long term chronic diseases (Neggers 2018). The American College of Obstetricians and Gynecologists defines "Infants born between 20 to 37 weeks of pregnancy are called 'preterm' or 'premature'. Infants born before 28 completed weeks of pregnancy are considered extremely preterm" (WHO 2019, ACOG 2019).

In this study, the overall preterm/premature delivery rate was extremely high, at 62.5 percent, with variations among HDP sub-types, including women with gestational hypertension who delivered prematurely (47.1\%) and women with severe PE/E (63.3\%). The extremely pre-term or premature rate $(<28$ weeks) was 4.3 percent among women with severe PE/E (Table 3). 
Table 3: Gestational profiles of women with Hypertensive Disorders in Pregnancy

\begin{tabular}{|c|c|c|c|}
\hline Type of HDP and Gestational Profile & $\begin{array}{c}\text { Number } \\
\text { (n) }\end{array}$ & $\begin{array}{c}\text { Percentage } \\
\text { (\%) }\end{array}$ & $\begin{array}{c}\text { Total } \\
(n=400)\end{array}$ \\
\hline \multicolumn{4}{|l|}{ Gestational Age at Onset of HDP } \\
\hline \multicolumn{3}{|l|}{ Chronic Hypertension } & 12 \\
\hline$<34$ weeks & 3 & 25.0 & \\
\hline$\geq 34$ weeks & 9 & 75.0 & \\
\hline \multicolumn{3}{|l|}{ Pre-Eclampsia } & 87 \\
\hline$<34$ weeks & 22 & 25.3 & \\
\hline$\geq 34$ weeks & 65 & 74.7 & \\
\hline \multicolumn{3}{|l|}{ Severe Pre-Eclampsia and Eclampsia } & 267 \\
\hline$<34$ weeks & 69 & 25.8 & \\
\hline$\geq 34$ weeks & 198 & 74.2 & \\
\hline \multicolumn{3}{|l|}{ Gestational Hypertension } & 34 \\
\hline$<34$ weeks & 7 & 20.6 & \\
\hline$\geq 34$ weeks & 27 & 79.4 & \\
\hline \multicolumn{4}{|l|}{ Gestational Age at Delivery } \\
\hline \multicolumn{3}{|l|}{ Choric Hypertension } & 12 \\
\hline$<28$ weeks & - & - & \\
\hline 28-36 weeks & 7 & 58.3 & \\
\hline$\geq 37$ weeks & 5 & 41.7 & \\
\hline \multicolumn{3}{|l|}{ Gestational Hypertension } & 34 \\
\hline$<28$ weeks & - & - & \\
\hline 28-36 weeks & 16 & 47.1 & \\
\hline$\geq 37$ weeks & 18 & 52.9 & \\
\hline \multicolumn{3}{|l|}{ Pre-Eclampsia } & 87 \\
\hline$<28$ weeks & - & - & \\
\hline 28-36 weeks & 47 & 54.0 & \\
\hline$\geq 37$ weeks & 40 & 46.0 & \\
\hline \multicolumn{3}{|l|}{ Severe Pre-Eclampsia and Eclampsia } & 267 \\
\hline$<28$ weeks & 11 & 4.3 & \\
\hline 28-36 weeks & 169 & 63.3 & \\
\hline$\geq 37$ weeks & 87 & 32.6 & \\
\hline
\end{tabular}

An infant's weight at birth is strongly associated with its mortality risk during the first year and, to a lesser degree, with developmental problems in childhood and risks of various diseases in adulthood (Wilcox 2001). WHO defines low birth weight as less than $2.5 \mathrm{~kg}$ at birth, regardless of gestational age (WHO 2019). In this study, the proportion of low birth weight ( $<2.5 \mathrm{~kg}$ ) infants was 58.8 percent among infants of women with HDP, ranging from 45.5 percent among infants of women with chronic hypertension to 64.5 percent among infants of women whose pregnancies were complicated by severe PE/E (Table 4, following page).

The relative risk of fetal death is remarkably high among pregnancies diagnosed with PE in the pre-term period (Harmon et al 2015). In this study, the overall stillbirth rate among women with HDPs was 15.3 percent, and varied by HDP sub-type, as shown in Table 3, with the highest rate among women with severe $\mathrm{PE} / \mathrm{E}(18 \%)$. In this study, the early neonatal death rate was 3.5 percent, particularly among women with $\mathrm{PE} / \mathrm{E}$ (Table 4). 
Table 4: Types of Hypertensive Disorders in Pregnancy, by outcome measures

\begin{tabular}{|c|c|c|c|}
\hline Type of HDP and Outcome Measures & $\begin{array}{l}\text { Number } \\
\text { (n) }\end{array}$ & $\begin{array}{l}\text { Percentage } \\
(\%)\end{array}$ & $\begin{array}{c}\text { Total } \\
(\mathrm{n}=400)\end{array}$ \\
\hline \multicolumn{3}{|l|}{ HDP categories and fetal weight (kg) } & $n=325^{2}$ \\
\hline \multicolumn{3}{|l|}{ Chronic Hypertension } & 11 \\
\hline$<2.5$ & 5 & 45.5 & \\
\hline $2.5-3.5$ & 6 & 54.6 & \\
\hline$>3.5$ & - & - & \\
\hline \multicolumn{3}{|l|}{ Gestational Hypertension } & 32 \\
\hline$<2.5$ & 15 & 46.9 & \\
\hline $2.5-3.5$ & 13 & 40.6 & \\
\hline$>3.5$ & 4 & 12.5 & \\
\hline \multicolumn{3}{|l|}{ Pre-Eclampsia } & 71 \\
\hline$<2.5$ & 35 & 49.3 & \\
\hline $2.5-3.5$ & 28 & 39.4 & \\
\hline$>3.5$ & 8 & 11.3 & \\
\hline \multicolumn{3}{|l|}{ Severe Pre-Eclampsia and Eclampsia } & 211 \\
\hline$<2.5$ & 136 & 64.5 & \\
\hline $2.5-3.5$ & 72 & 34.1 & \\
\hline$>3.5$ & 3 & 1.4 & \\
\hline \multicolumn{4}{|l|}{ HDP categories versus fetal outcomes } \\
\hline \multicolumn{3}{|l|}{ Chronic Hypertension } & 12 \\
\hline Alive & 11 & 91.7 & \\
\hline Stillbirth & 1 & 8.3 & \\
\hline Early neonatal death $(<7$ days postnatal) & 0 & 0.0 & \\
\hline \multicolumn{3}{|l|}{ Gestational Hypertension } & 34 \\
\hline Alive & 32 & 94.1 & \\
\hline Stillbirth & 2 & 5.9 & \\
\hline Early neonatal death ( $<7$ days postnatal) & 0 & 0.0 & \\
\hline \multicolumn{3}{|l|}{ Pre-Eclampsia } & 87 \\
\hline Alive & 71 & 81.6 & \\
\hline Stillbirth & 10 & 11.5 & \\
\hline Early neonatal death $(<7$ days postnatal) & 6 & 6.9 & \\
\hline \multicolumn{3}{|l|}{ Severe Pre-Eclampsia and Eclampsia } & 267 \\
\hline Alive & 211 & 79.0 & \\
\hline Stillbirth & 48 & 18.0 & \\
\hline Early neonatal death $(<7$ days postnatal) & 8 & 3.0 & \\
\hline
\end{tabular}

Table 5 (on the following page) shows the pattern of hypertension severity among women who suffered from HDP during all four timeframes; this analysis was only for those women whose data were available for all four points of data collection $(n=21)$. Findings show that hypertension persisted in some participants over a year, and also show that when hypertension persists beyond nine weeks, it tends to be mild to moderate (systolic $\geq 160 \mathrm{mmHg}$, and or diastolic $\geq 110 \mathrm{mmHg}$ ) for chronic hypertension, and mild to moderate or severe for PE and eclampsia. 
Table 5: Pattern of hypertension, severity and progression for all follow up periods, by types of Hypertensive Disorder in Pregnancy $(n=21)$

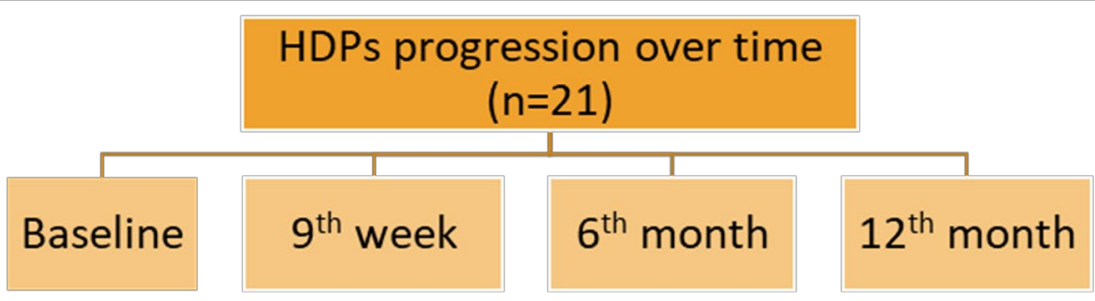

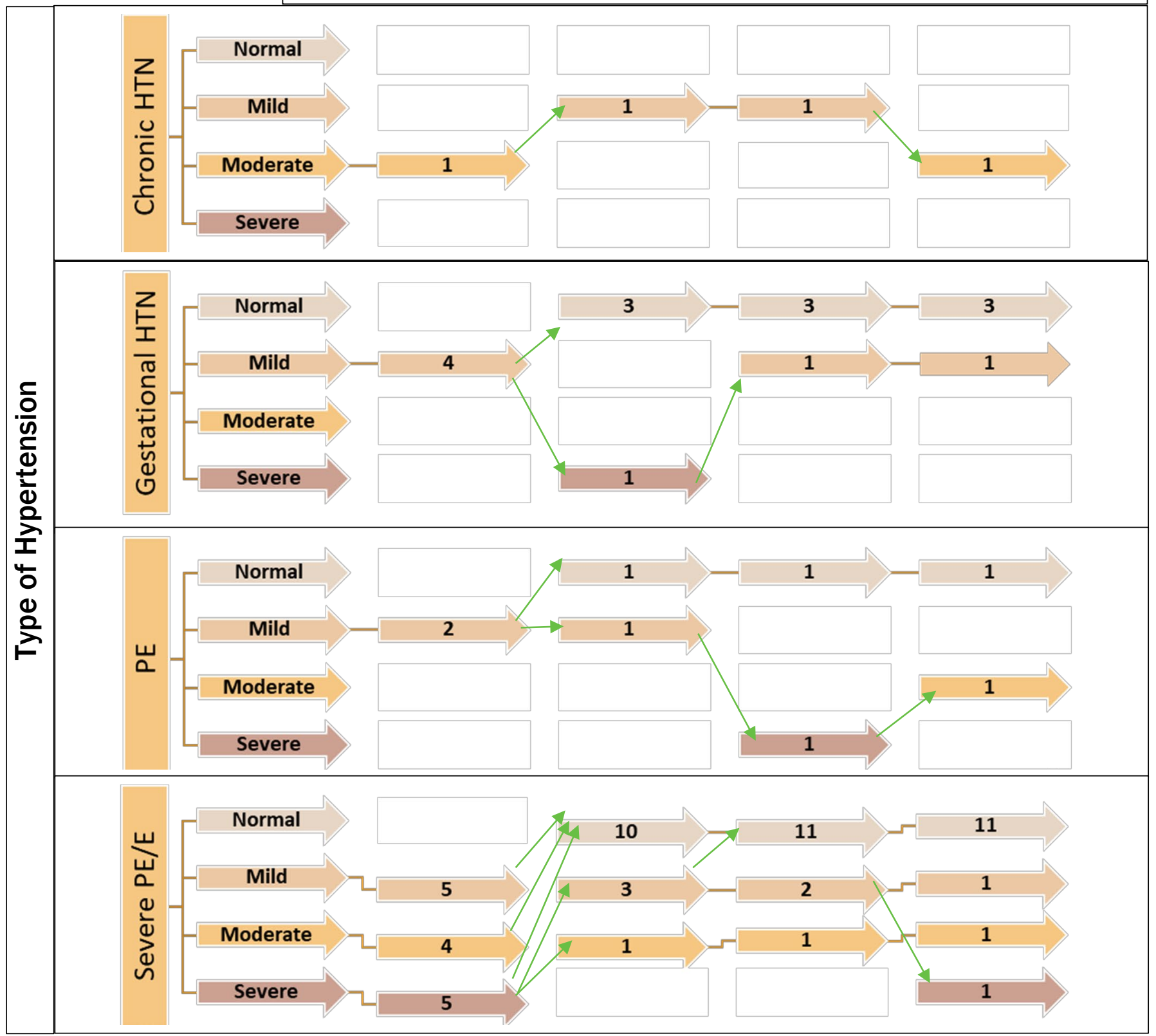




\begin{tabular}{|c|c|c|c|c|c|c|c|c|c|}
\hline \multirow{3}{*}{ HDP Type } & \multicolumn{9}{|c|}{ Data collection points and HDP progression } \\
\hline & \multicolumn{2}{|c|}{ Baseline } & \multicolumn{2}{|c|}{ Ninth week } & \multicolumn{2}{|c|}{ Sixth month } & \multicolumn{2}{|c|}{$12^{\text {th }}$ month } & \multirow[b]{2}{*}{$\mathrm{n}$} \\
\hline & $\mathbf{n}$ & BP level & $\mathrm{n}$ & $\begin{array}{c}\text { BP } \\
\text { progression }\end{array}$ & $\mathbf{n}$ & $\begin{array}{c}\mathrm{BP} \\
\text { progression }\end{array}$ & $\mathrm{n}$ & $\begin{array}{c}\mathrm{BP} \\
\text { progression }\end{array}$ & \\
\hline $\begin{array}{l}\text { Chronic } \\
\text { Hypertension }\end{array}$ & 1 & Moderate & 1 & Mild & 1 & Mild & 1 & Moderate & 1 \\
\hline \multirow{2}{*}{$\begin{array}{l}\text { Gestational } \\
\text { Hypertension }\end{array}$} & & & 3 & Normal & 3 & Normal & 3 & Normal & 3 \\
\hline & 4 & Mild & 1 & Severe & 1 & Mild & 1 & Mild & 1 \\
\hline \multirow{2}{*}{ Pre-Eclampsia } & & & 1 & Normal & 1 & Normal & 1 & Normal & 1 \\
\hline & 2 & Mild & 1 & Mild & 1 & Severe & 1 & Moderate & 1 \\
\hline \multirow{4}{*}{ Severe PE/E } & & & & & & & 11 & Normal & 11 \\
\hline & 5 & Mild & 3 & Mild & 2 & Mild & 1 & Mild & 1 \\
\hline & 4 & Moderate & 1 & Moderate & 1 & Moderate & 1 & Moderate & 1 \\
\hline & 5 & Severe & 10 & Normal & 11 & Normal & 1 & Severe & 1 \\
\hline Total & 21 & & 21 & & 21 & & 21 & & 21 \\
\hline
\end{tabular}

\section{Quality of Postnatal Care for Women and Their Infants}

It is generally recommended that women with HDPs have their BP measured daily, for the first two days after birth, for chronic and gestational HTN, at least four times a day while a woman is a PE/E in-patient, and at least once between the third and fifth days following birth for all sub-types (NICE 2019). In this study, up to 89 percent of women with HDPs had their BP measured and documented on the first day, but the proportion progressively declined, as shown in Figure 3, and slightly increased on the day of discharge (fifth day postnatal).

Figure 3: Percentage of women with Hypertensive Disorders in Pregnancy with BP measured and documented (from day 1 to day 5 and discharge day) $(n=400)$

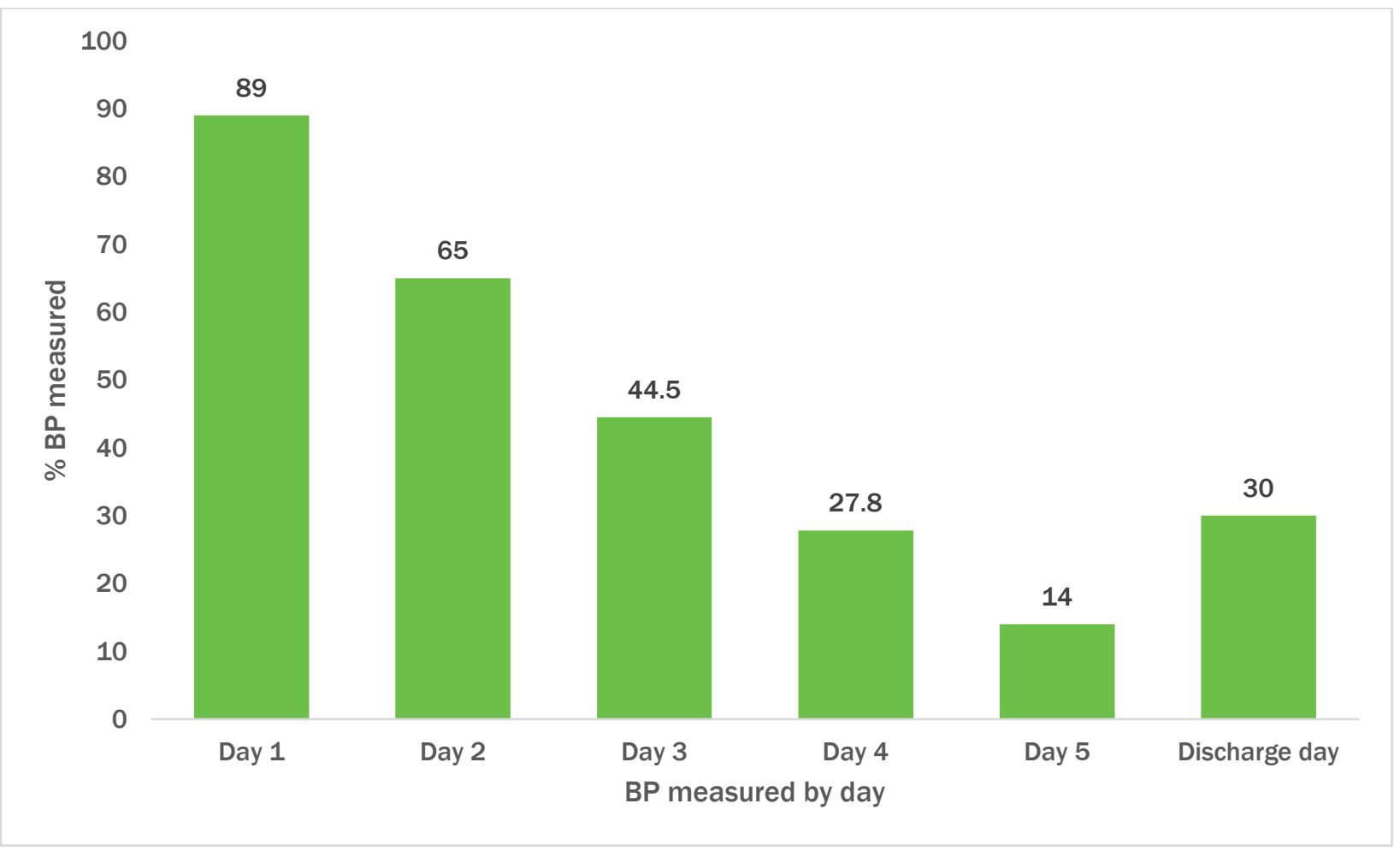


Similarly, up to 73 percent of women with HDPs had their urine checked and documented on the first day, but the proportion of women whose urine was checked and documented progressively declined thereafter, as shown in Figure 4, and increasing slightly on the day of discharge (sixth day postnatal).

Figure 4: Percentage of women with Hypertensive Disorders in Pregnancy with urine checked and documented (from day 1 to day 5 and discharge day) $(n=400)$

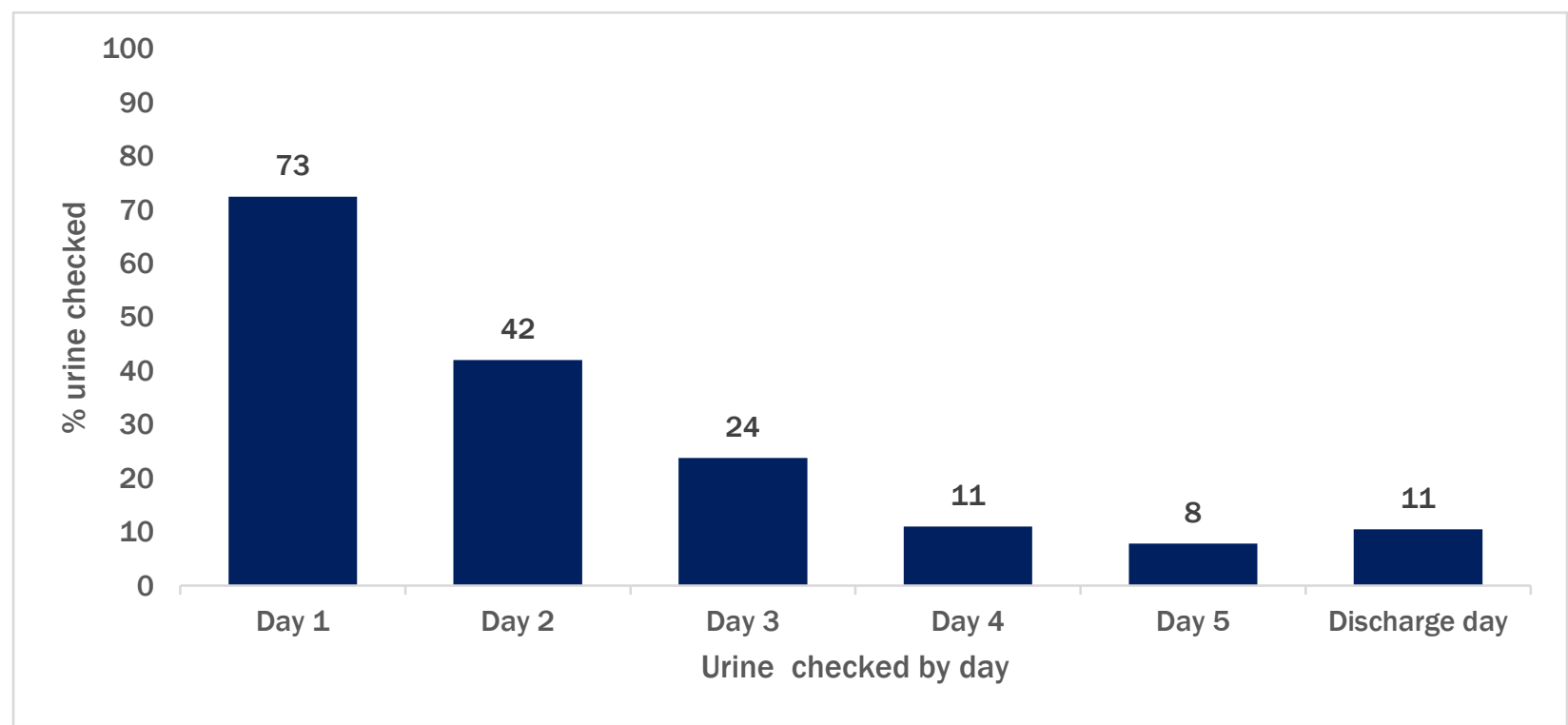

Table 6 shows levels of urine albumin among women with HDPs for each day surveyed (from day 1 to day 5 and discharge day). While urine monitoring and documentation declined each day until day of discharge, still 11 percent of women had albumin in their urine at different levels (31\% women had $\geq 2+$ albumin) on day of discharge.

Table 6: Percentage of women with Hypertensive Disorders in Pregnancy with urine checked and documented and level of urine albumin (From day 1 to discharge day) $(n=400)$

\begin{tabular}{|l|c|c|c|c|c|c|}
\hline \multirow{3}{*}{ Day of check } & \multicolumn{7}{|c|}{ Urine checked and level of urine albumin } \\
\cline { 2 - 7 } & $\begin{array}{c}\text { Yes } \\
\mathrm{n}(\%)\end{array}$ & $\begin{array}{c}\text { Trace } \\
\mathrm{n}(\%)\end{array}$ & $\begin{array}{c}1+ \\
\mathrm{n}(\%)\end{array}$ & $\begin{array}{c}2+ \\
\mathrm{n}(\%)\end{array}$ & $\begin{array}{c}3+ \\
\mathrm{n}(\%)\end{array}$ & $\begin{array}{c}4+ \\
\mathrm{n}(\%)\end{array}$ \\
\hline Day 1 & $290(72.5)$ & $56(19.3)$ & $42(14.5)$ & $46(15.9)$ & $57(19.7)$ & $89(30.7)$ \\
\hline Day 2 & $168(42.0)$ & $57(33.9)$ & $52(30.9)$ & $32(19.1)$ & $17(10.1)$ & $10(5.9)$ \\
\hline Day 3 & $95(23.8)$ & $41(43.2)$ & $23(24.2)$ & $15(15.8)$ & $12(12.6)$ & $4(4.2)$ \\
\hline Day 4 & $44(11.0)$ & $17(38.6)$ & $12(27.3)$ & $9(20.5)$ & $6(13.6)$ & - \\
\hline Day 5 & $31(7.8)$ & $13(41.9)$ & $7(22.6)$ & $4(12.9)$ & $7(22.6)$ & - \\
\hline Discharge day & $42(10.5)$ & $21(50.0)$ & $8(19.1)$ & $7(16.7)$ & $5(11.9)$ & $1(2.4)$ \\
\hline
\end{tabular}

It is recommended that all women with HDPs should continue anti-hypertensive medication until their BP is well-controlled. A target BP level is systolic less than $140 \mathrm{mmHg}$ and diastolic less than $90 \mathrm{mmHg}$ (NICE 2013). This study assessed the medical records of women with HDP to determine the extent of compliance with this recommendation. About 30 percent of women who experienced PE with moderate hypertension $(\mathrm{BP} \geq 150 / 100 \mathrm{mmHg}$ ) were not on anti-hypertensive medication during their first week postnatal, and 23.9 percent of women who experienced severe PE/E were not on anti-hypertensive drugs after giving birth (Figure 5, following page). 
Figure 5: Percentage of women with moderate to severe hypertension (BP $\geq 150 / 100 \mathrm{mmHg}$ ) on anti-hypertensive treatment within a week of delivery, by type of $\operatorname{HDP}(\mathrm{N}=277)^{3}$

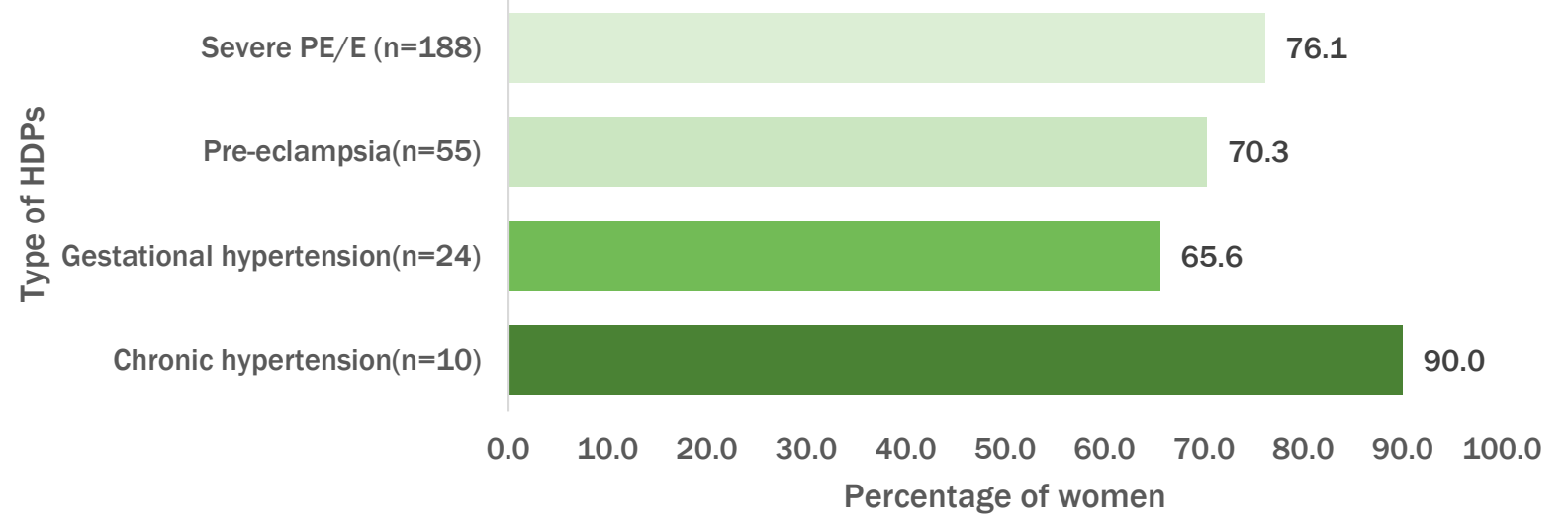

It is recommended that women suffering from HDPs receive continued care and counseling services for six to eight weeks following delivery. Four hundred admitted HDP women's in-patient records reviews reveal poor quality of care and counseling, as well as poor documentation. Women with HDPs should receive information on danger signs (severe headache, blurred vision, nausea or vomiting, epigastric pain) when being discharged from a health facility, and only two records reviewed document this. No records document counseling on HDP risk for future pregnancy, nor on seeking early ANC or family planning (FP) counseling. No women's files document thromboprophylaxis after delivery.

While the quality of all other care and counseling were poor, almost all women who remained hypertensive were offered medical review at two weeks (99.3\%) as well as six to eight weeks after discharge (98.5\%), documented. Around one quarter (25.3\%) of newborns received clinical and feeding assessments (23.5\%) two to three days after birth. Only 11 percent of infants, however, are documented as being seen by a neonatologist (data not shown).

Table 7: Percentage of women with HDPs who received appropriate care and counseling, from record reviews during hospitalization

\begin{tabular}{|c|c|c|c|}
\hline \multirow[b]{2}{*}{ Counseling and services } & \multicolumn{2}{|c|}{ Received } & \multirow[b]{2}{*}{$\begin{array}{c}\text { Total } \\
(n)\end{array}$} \\
\hline & $\begin{array}{l}\text { Yes } \\
\text { n (\%) }\end{array}$ & $\begin{array}{c}\text { No } \\
n(\%)\end{array}$ & \\
\hline $\begin{array}{l}\text { Received information on danger signs } \\
\text { (severe headache, blurred vision, nausea, vomiting, epigastric pain) }\end{array}$ & $2(0.5)$ & 398 (99.5) & 400 \\
\hline Offered medical check up 2 weeks after hospital discharge & $397(99.3)$ & $3(0.7)$ & 400 \\
\hline Offered medical review at 6 to 8 week postpartum visits & $394(98.5)$ & $6(1.5)$ & 400 \\
\hline Had PE/E and received thromboprophylaxis after delivery & $0(0.0)$ & $400(100.0)$ & 400 \\
\hline $\begin{array}{l}\text { Had PE/E and offered urine protein estimation } 6 \text { to } 8 \text { weeks } \\
\text { postpartum }\end{array}$ & $0(0.0)$ & $388(100.0)$ & 388 \\
\hline $\begin{array}{l}\text { Clinical well-being of infant assessed daily for first } 2 \text { to } 3 \text { days } \\
\text { after delivery }\end{array}$ & $83(25.3)$ & $245(74.7)$ & 328 \\
\hline Infant feeding assessed daily for 2 to 3 days after delivery & $77(23.5)$ & $251(76.5)$ & 328 \\
\hline Counseled on FP any time after delivery & $1(0.3)$ & $399(99.7)$ & 400 \\
\hline Counseled to attend ANC early in next pregnancy & $0(0.0)$ & $400(100.0)$ & 400 \\
\hline Counseled on risk of condition recurrence in subsequent pregnancy & $0(0.0)$ & $400(100.0)$ & 400 \\
\hline Infant assessed by neonatologist & $38(11.6)$ & $290(88.4)$ & 328 \\
\hline
\end{tabular}

3133 women with HDPs information were missing in the records and were not included in this analysis 


\section{Women's Perceptions and Experiences with HDPs and Their Care}

Women $(n=48)$ were asked about their perceptions and experiences of their quality of clinical care and counseling services at their nine week follow up visit. In general, the quality of their counseling was perceived as poor, as recalled by patients themselves (Table 8).

Table 8: Women with HDP's perceptions and experiences of care, at ninth week after delivery (women's recall)

\begin{tabular}{|c|c|c|c|}
\hline \multirow[b]{2}{*}{ Women's perceptions and experiences of their care } & \multicolumn{2}{|c|}{ Received } & \multirow[b]{2}{*}{$\begin{array}{c}\text { Total } \\
(n)\end{array}$} \\
\hline & $\begin{array}{l}\text { Yes } \\
(\%)\end{array}$ & $\begin{array}{l}\text { No } \\
(\%)\end{array}$ & \\
\hline $\begin{array}{l}\text { When you were told that you have one of the hypertensive conditions in } \\
\text { pregnancy, did you understand what that meant? }\end{array}$ & $4(8.3)$ & $44(91.7)$ & 48 \\
\hline $\begin{array}{l}\text { Did the health care provider find time to explain what the condition } \\
\text { means and its implication for your health and that of your baby? }\end{array}$ & $5(10.4)$ & $43(89.6)$ & 48 \\
\hline Were you given the opportunity to ask questions for clarification? & $6(12.5)$ & $42(87.5)$ & 48 \\
\hline Is this the first time you have had this type condition in pregnancy? & $40(83.3)$ & $8(16.7)$ & 48 \\
\hline Has anyone in your family had this kind of condition in the past? & $27(56.3)$ & $21(43.8)$ & 48 \\
\hline $\begin{array}{l}\text { Did you have any concerns when you were informed that you developed } \\
\text { hypertension in pregnancy? }\end{array}$ & $45(93.8)$ & $3(6.3)$ & 48 \\
\hline Have you discussed this concern with your health care providers? & $18(40.0)$ & $27(60.0)$ & 45 \\
\hline Did you receive satisfactory feedback from your service providers? & $12(66.7)$ & $6(33.3)$ & 18 \\
\hline $\begin{array}{l}\text { Do you think you have received the right care and information from your } \\
\text { care providers during pregnancy with this condition? }\end{array}$ & 35 (72.9) & $13(27.1)$ & 48 \\
\hline $\begin{array}{l}\text { Did you suffer from any complication in this pregnancy as a result of this } \\
\text { condition? }\end{array}$ & $46(95.8)$ & $2(4.2)$ & 48 \\
\hline $\begin{array}{l}\text { Now that you have given birth, do you think that your caregivers have } \\
\text { given you sufficient information about your future health } \\
\text { after a pregnancy affected by hypertension? }\end{array}$ & $0(0.0)$ & $48(100.0)$ & 48 \\
\hline $\begin{array}{l}\text { Is knowing how this condition can be prevented in pregnancy something } \\
\text { you are particularly interested in? }\end{array}$ & $21(43.7)$ & $27(56.3)$ & 48 \\
\hline $\begin{array}{l}\text { If you are planning another baby in the future, have you been counseled } \\
\text { on how to prevent this condition in future pregnancy? }\end{array}$ & $1(3.7)$ & $26(96.3)$ & 27 \\
\hline
\end{tabular}

\section{Clinical Courses of Women with Hypertensive Disorders in Pregnancy}

Six out of 21 women with various sub-types of HDP at baseline who attended all three follow ups over a year remained hypertensive over the entire period; yet some women's BP rapidly dropped (Table 5).

Women in the study who received health checks for a year were tested for metabolic functions. Table 9 (following page) shows that numerous women's metabolic functions deviated from normal. Meanwhile, Table 10 (page 18) shows that at baseline not all women were tested, or documented, for all required metabolic functions. For example, 67 (17\%) of 400 women with HDPs were tested, or at least documented, for serum creatinine, and among those 77.6 percent had high levels. Similarly, 69.5 percent of 400 women with HDPs had proteinuria at baseline, and although in general these levels improved over time, 3.1 percent had abnormal protein excretion after a year, suggesting possible permanent kidney impairment (Table 9).

Although also improving over time, 6.3 percent of women with HDP had persistent high creatinine levels for a year, suggesting further possible permanent kidney impairment. Similar patterns of persistent disparity were observed for glucose intolerance, liver enzymes (Alanine and Aspartate transaminases), serum cholesterol, and triglycerides (Table 9). These findings indicate that women with HDPs need long term monitoring and review of required metabolic functions to prevent and treat long term morbidities. 
Table 9: Prevalence of metabolic disorders over one year since delivery among women with HDP

\begin{tabular}{|c|c|c|c|c|c|c|}
\hline \multirow[t]{2}{*}{ Metabolic disorder } & \multicolumn{2}{|c|}{$\begin{array}{l}\text { Baseline } \\
(n=400)\end{array}$} & \multirow{2}{*}{$\begin{array}{c}\begin{array}{c}9 \text { weeks } \\
(n=48)\end{array} \\
n(\%)\end{array}$} & \multirow{2}{*}{$\begin{array}{c}6 \text { months } \\
(\mathrm{n}=26)\end{array}$} & \multirow{2}{*}{$\begin{array}{c}\begin{array}{c}1 \text { Year } \\
(n=32)\end{array} \\
n(\%)\end{array}$} & \multirow{2}{*}{$\begin{array}{l}\text { Laboratory } \\
\text { reference value }\end{array}$} \\
\hline & Total & $\mathrm{n}(\%)$ & & & & \\
\hline Persistent proteinuria & 400 & $\begin{array}{c}278 \\
(69.5) \\
\end{array}$ & $4(8.3)$ & $2(7.6)$ & $1(3.1)$ & Normal: Nil \\
\hline $\begin{array}{l}\text { Glucose intolerance } \\
(\mathrm{mmol} / \mathrm{L})\end{array}$ & 41 & $5(12.2)$ & $4(8.3)$ & $3(11.5)$ & $5(15.6)$ & $\begin{array}{l}\text { Normal : }<7.8 \\
\mathrm{mmol} / \mathrm{L}\end{array}$ \\
\hline $\begin{array}{l}\text { High serum urea } \\
(\mathrm{mmol} / \mathrm{L})\end{array}$ & 16 & $12(75.0)$ & $0(0.0)$ & $1(3.9)$ & $0(0.0)$ & $\begin{array}{l}\text { Normal: } 1.9-8.3 \\
\mathrm{mmol} / \mathrm{L}\end{array}$ \\
\hline $\begin{array}{l}\text { High serum creatinine } \\
(\mathrm{mmol} / \mathrm{L})\end{array}$ & 67 & $52(77.6)$ & $33(68.8)$ & 9 (34.6) & $2(6.3)$ & $\begin{array}{l}\text { Normal: } 53-120 \\
\mathrm{mmol} / \mathrm{L}\end{array}$ \\
\hline $\begin{array}{l}\text { Low platelets count } \\
(\mathrm{mL})\end{array}$ & 77 & $12(15.6)$ & $5(10.4)$ & $2(7.7)$ & $0(0.0)$ & $\begin{array}{l}\text { Normal: } 150,000- \\
300,000 / \mathrm{mL}\end{array}$ \\
\hline $\begin{array}{l}\text { Elevated aspartate } \\
\text { transferase }(\mathrm{U} / \mathrm{L})\end{array}$ & 37 & $16(43.2)$ & $1(2.1)$ & $5(19.2)$ & $4(12.5)$ & $\begin{array}{l}\text { Normal: up to } 40 \\
\mathrm{U} / \mathrm{L}\end{array}$ \\
\hline $\begin{array}{l}\text { Elevated alanine } \\
\text { transferase }(\mathrm{U} / \mathrm{L})\end{array}$ & 55 & $12(21.8)$ & $9(18.8)$ & $11(42.3)$ & $11(34.4)$ & $\begin{array}{l}\text { Normal: up to } 40 \\
\mathrm{U} / \mathrm{L}\end{array}$ \\
\hline $\begin{array}{l}\text { High total serum } \\
\text { cholesterol (mg/dL) }\end{array}$ & - & - & $18(37.5)$ & $10(38.5)$ & 9 (28.1) & $\begin{array}{l}\text { Normal: up to } 200 \\
\mathrm{mg} / \mathrm{dL}\end{array}$ \\
\hline $\begin{array}{l}\text { High HDL cholesterol } \\
(\mathrm{mg} / \mathrm{dL})\end{array}$ & - & - & $11(23.9)$ & $6(23.1)$ & $14(43.8)$ & $\begin{array}{l}\text { Normal: up to } 60 \\
\mathrm{mg} / \mathrm{dL}\end{array}$ \\
\hline $\begin{array}{l}\text { High LDL cholesterol } \\
(\mathrm{mg} / \mathrm{dL})\end{array}$ & - & - & $17(37.8)$ & 9 (34.6) & $6(18.8)$ & $\begin{array}{l}\text { Normal up to } 130 \\
\mathrm{mg} / \mathrm{dL}\end{array}$ \\
\hline $\begin{array}{l}\text { High serum triglycerides } \\
(\mathrm{mg} / \mathrm{dL})\end{array}$ & - & - & $22(45.8)$ & $13(50.0)$ & $16(50.0)$ & $\begin{array}{l}\text { Normal: up to } 150 \\
\mathrm{mg} / \mathrm{dL}\end{array}$ \\
\hline
\end{tabular}

$"="$ not tested

Table 10 provides the complication signs and symptoms of women with HDP for a year after delivery; women enrolled in the study who attended three follow up consultations were included in the analysis.

The record review revealed that women with HDPs had a number of complications including headache (45\%), blurred vision (22\%), albuminuria (69.5\%), and high BP (94.3\%), among others. Those who continued follow up during the year following their delivery $(n=32)$ had persistent residual complications including severe headache (56.3\%), blurred vision (37.5\%), albuminuria (12.5\%), and high BP (37.5\%).

Table 10: Women with complications, their signs and symptoms, one year after delivery

\begin{tabular}{|l|c|c|c|c|}
\hline Complication & $\begin{array}{c}\text { Baseline }(\mathrm{n}=400) \\
\mathrm{n}(\%)\end{array}$ & $\begin{array}{c}9 \text { weeks }(\mathrm{n}=48) \\
\mathrm{n}(\%)\end{array}$ & $\begin{array}{c}6 \text { months }(\mathrm{n}=26) \\
\mathrm{n}(\%)\end{array}$ & $\begin{array}{c}12 \text { months }(\mathrm{n}=32) \\
\mathrm{n}(\%)\end{array}$ \\
\hline Loss of orientation & - & 0 & $5(19.2)$ & $3(9.4)$ \\
\hline Severe headache & $179(45.0)$ & $13(27.1)$ & $11(42.3)$ & $18(56.3)$ \\
\hline Blurred vision & $87(22.0)$ & $11(22.9)$ & $9(34.6)$ & $12(37.5)$ \\
\hline Jaundice & $13(3.3)$ & $1(2.1)$ & 0 & 0 \\
\hline Chest pain & - & $1(2.1)$ & 0 & 0 \\
\hline Abdominal pain & $41(10.3)$ & $2(4.2)$ & $3(11.5)$ & $2(6.3)$ \\
\hline Diminished urine output & $6(1.5)$ & 0 & 0 & 0 \\
\hline Urine albumin & $278(69.5)$ & $6(12.5)$ & $7(26.9)$ & $4(12.5)$ \\
\hline Elevated BP & $377(94.3)$ & $17(35.4)$ & $7(26.9)$ & $12(37.5)$ \\
\hline
\end{tabular}




\section{Clinical Courses of Infants}

The infants of women who attended all three PNC follow ups-at nine weeks, six months, and 12 monthswere also assessed. Table 11 lists the health and developmental parameters collected at the three points in time. At nine weeks, the mean weight of infants was $4.5 \mathrm{~kg}$, with $1.3 \mathrm{~kg}$ standard deviation; at six months it was $7.5 \mathrm{~kg}$, with $1.8 \mathrm{~kg}$ standard deviation, and at 12 months it was $9.5 \mathrm{~kg}$, with 1.3 standard deviation. Stillbirth occurrence was 15.3 percent, and the neonatal death rate ( $<7$ days) was 3.5 percent.

Table 11: Changes in infants' clinical developmental parameters, by data collection points in time

\begin{tabular}{|c|c|c|c|}
\hline \multirow[b]{2}{*}{ Parameter } & \multicolumn{3}{|c|}{ Data collection points } \\
\hline & $\begin{array}{c}9 \text { weeks } \\
(\text { mean } \pm S D) \\
(\mathrm{n}=35)\end{array}$ & $\begin{array}{c}6 \text { months } \\
(\text { mean } \pm S D) \\
(\mathrm{n}=17)\end{array}$ & $\begin{array}{c}12 \text { months } \\
(\text { mean } \pm S D) \\
(\mathrm{n}=25)\end{array}$ \\
\hline Baby weight (kg) & $4.5 \pm 1.3$ & $7.5 \pm 1.8$ & $9.5 \pm 1.3$ \\
\hline Baby length $(\mathrm{cm})$ & $49.2 \pm 13.6$ & $62.7 \pm 4.1$ & $71.5 \pm 7.3$ \\
\hline Occipitofrontal circumference $(\mathrm{cm})$ & $35.4 \pm 8.3$ & $42.9 \pm 2.4$ & $45.4 \pm 4.1$ \\
\hline Systolic BP (mmHg) & $81.3 \pm 15.1$ & $89.8 \pm 8.2$ & $85.1 \pm 11.6$ \\
\hline Diastolic BP (mmHg) & $51.1 \pm 11.4$ & $56.8 \pm 6.6$ & $54.0 \pm 8.9$ \\
\hline Heart rate $(/ \mathrm{min})$ & $97.1 \pm 23.5$ & $96.4 \pm 14.3$ & $94.5 \pm 8.9$ \\
\hline Respiratory rate(/min) & $40.1 \pm 9.2$ & $43.1 \pm 7.1$ & $36.2+9.2$ \\
\hline Outcomes & & & $n=400$ \\
\hline
\end{tabular}

Similarly, Table 12 lists the changes in infant developmental achievement for three data collection pointsat nine weeks, six months, and 12 months-among women and their infants who attended all three follow ups. For all parameters measured, most infants achieved their developmental milestones.

Table 12: Percentage of infants' developmental changes, by data collection points in time

\begin{tabular}{|l|c|c|c|}
\hline \multirow{2}{*}{ Parameter } & \multicolumn{3}{|c|}{ Data collection points } \\
\cline { 2 - 4 } & $\begin{array}{c}9 \text { weeks } \\
(n=35)\end{array}$ & $\begin{array}{c}6 \text { months } \\
(n=17)\end{array}$ & $\begin{array}{c}12 \text { months } \\
(n=25)\end{array}$ \\
\hline Social smile & $34(97.1)$ & $17(100.0)$ & $25(100.0)$ \\
\hline Neck control & $34(97.1)$ & $16(94.1)$ & $25(100.0)$ \\
\hline Sitting & - & $9(52.9)$ & $25(100.0)$ \\
\hline Crawling & - & $2(11.8)$ & $25(100.0)$ \\
\hline Standing with support & - & $1(5.8)$ & $25(100.0)$ \\
\hline Walking & - & - & $7(28.0)$ \\
\hline
\end{tabular}




\section{Discussion}

This report results from a prospective cohort study of married women with HDP recruited around the time of their deliveries, who were then followed for 12 months, without any comparison group: 400 women with HDPs were admitted to Dhaka Medical College and Hospital, with the expectation of 166 recruited over six months for follow up-and 160 women consented. In reality, however, only 48 (30\%) consenting women actually returned for follow up at nine weeks, while 26 (16.3\%) returned at six months, and 32 (20\%) returned at 12 months. Follow up attendance was poor even with repeated contacts with the women enrolled in the study. The reasons offered by women for their failure to return for follow up care included traffic jams, too much time necessary for travel, distance, lack of travel companions, and perceived absence of necessary because to feeling well, among others. The women were recruited at a high volume tertiary care hospital that serves patients in Dhaka district as well as from other parts of the country.

As this was an empirical study with repeated, planned contacts for follow up resulting in a small proportion of women actually returning for care, real life scenarios may be even worse. Providers should counsel all women with HDPs on the importance of recommended follow ups, and patients should be adequately educated for their compliance with care for their future health. As the number of patients who completed three follow up visits was much lower than expected, these findings should be interpreted with caution.

About half of women with HDP admitted to DMCH were from the Dhaka catchment area (47\%). Although all of the women in the study live closer to a facility providing ANC, record reviews suggest poor ANC patterns among these women. A large number of women requiring emergency admission to a tertiary care facility for delivery complication management suggests poor ANC-seeking behaviors, along with poor quality ANC and PNC services at lower level facilities, and widespread lack of capacity for managing delivery complications with HDP. This indicates weaknesses within the health care system, particularly for pregnant women's care. The Bangladesh Demographic and Health Survey 2017 revealed only 47 percent of women with WHO-recommended four or more ANC visits for their most recent birth (Niport et al 2018, WHO 2018), with poor PNC as well, where about half of women seek none after delivery (Niport et al 2018).

Infant birthweight is strongly associated with mortality risk during the first year and, to a lesser degree, childhood developmental problems and risk of various diseases in adulthood (Wilcox 2001). Low birthweight is associated with poor cognitive development and chronic adult disease-type 2 diabetes, hypertension, and cardiovascular disease (Halbreich 2005). WHO defines LBW as less than $2.5 \mathrm{~kg}$.

Bangladesh has the highest incidence of LBW (22.6\%) in Asia, with 80 percent of all LBW newborns born at term (IPHN 2017, Arifeen 1997, ACC/SCN 2000). While the national LBW average is 23 percent; this study found an extremely high percentage of LBW infants (58.8\%) among women suffering from HDP, and about two thirds (62.5\%) were also pre-term or premature. LBW was even higher among women suffering from severe PE/E (64.5\%). These results call for action to adequately control women's BP throughout $e$ pregnancy regardless of underlying pathological factors, in addition to providing adequate nutrition.

It is now widely accepted that there are two different etiologies of $\mathrm{PE} / \mathrm{E}$, differentiated by gestational age at onset, frequently described as early onset (EO, <34 weeks gestation) and late onset (LO, $\geq 34$ weeks gestation). There are differences in terms of biological markers, clinical manifestation, maternal and perinatal outcome, prognosis, and complication (Huppertz 2008, Gomathy et al 2018). EO-PE is the most severe clinical variant, occurring in five percent to 20 percent of all PE cases and is associated with fetal growth restriction and adverse maternal and neonatal outcomes. LO-PE occurs in about 75 percent to 80 percent of all PE cases, associated with maternal morbidity but more favorable perinatal outcomes (Madazi et al 2018, Sulistyowati et al 2017). Overall EO-PE in this study is 25.3 percent, slightly higher than global incidence (Madazi et al 2018). 
Special consideration should be given to EO-PE, as it is more severe and life-threatening. Low dose aspirin (75mg) is a useful prophylactic, particularly among high risk patients at an early stage compared to LO-PE (WHO 2011). Routine prophylactic low dose aspirin (75mg) for women at risk of PE should be encouraged and strengthened in Bangladesh.

Currently, pre-term or premature birth (between 20 to 37 weeks of pregnancy) is the leading cause of death among children under five around the world, and a leading cause of disability and ill health later in life. SubSaharan Africa and South Asia account for over 60 percent of pre-term births worldwide (Every Preemie Scale 2018). Bangladesh's national average of pre-term or premature birth is 14 percent, but 26 percent for women with HDPs (ibid). This study's pre-term or premature birth rate is much higher (63.3\%), including an extremely pre-term or premature rate ( $<28$ weeks) of 4.3 percent among women with severe PE/E. Although this study was conducted at a tertiary hospital addressing all emergencies, this rate of pre-term or premature delivery among women with HDP seems high, and needs further explanation. One reason for this elevated rate could be the small sample size. WHO estimates, using data from 184 countries, rates of premature delivery from five percent to 18 percent (WHO 2019, Blencowe et al 2012). These reports do not mention any rates among women with HDP, and there are many reasons for pre-term delivery.

Globally, stillbirth remains a significant public health issue, particularly in developing countries such as Bangladesh. Bangladesh is a major contributor to stillbirth rates in South Asia (Lawn et al 2016), with a reported stillbirth rate of 20 per 1,000 live births in 2015 (Bhutta et al 2016). Analysis of Bangladesh Demographic and Health Surveys data for 2004, 2007, 2011, and 2014 reveal a stillbirth rate of 28 per 1,000 births. Lack of maternal education, primiparity, and household poverty are considered predictors of stillbirth in Bangladesh (Tanvir et al 2015).

While there is a lack of enough clinical data on stillbirths among women with HDP, this study suggests a high stillbirth rate, of 15.3 percent, among women with HDP. A population-based surveillance study $(n=6,333)$ in four districts of Bangladesh revealed the three most frequent causes of stillbirth as maternal hypertension or eclampsia (15.2\%), antepartum hemorrhage (13.7\%), and maternal infections (8.9\%), with a stillbirth rate of 20.4 per 1,000 births (Halim et al 2018). These findings indicate the need for improved quality of ANC and intrapartum care.

This study reveals that quality of care for women experiencing HDP at a tertiary hospital is largely suboptimal. UK's NICE clinical guidelines recommend measuring BP for the first three days after delivery, and at least once more before the fifth day, for women with HDP (NICE 2011). While this recommendation was followed for 89 percent of women on the first day postnatal, adherence progressively declined over the following four days, and by the fifth day BP was not checked in most (84\%) women. This huge gap could be due, however, in part to lack of documentation of BP measurement.

Urine albumin analysis was also not performed as recommended. Eleven percent of women were recorded as having albumin in their urine on the day of discharge, and if all women were in fact checked upon discharge, this figure-an indicator for long term monitoring and follow up of women with HDPs-would likely be much higher. These gross omissions or oversights in the care of women with HDPs could be lifethreatening, as adverse cardiovascular events can occur three to five days after delivery due to uncontrolled high BP (Payne et al 2016).

Similar quality of care lapses were identified for anti-hypertensive drug coverage during the immediate postnatal period. Overall, 74.7 percent of women with moderate to severe hypertension received antihypertensive treatment immediately following delivery (within 7 days). While 90 percent of women with chronic hypertension were recommended to continue anti-hypertensive treatment the first week after delivery, among women with PE who required continued anti-hypertensive coverage (BP $\geq 150 / 100 \mathrm{mmHg}$ ), 30 percent were on no medication their first week postnatal; and the percentage was higher among women 
with gestational hypertension (33.4\%). Besides insufficient management of BP in the immediate postnatal period, poor adherence to clinical guidelines was seen in other aspects of care, particularly patient counseling.

It is recommended that all women with $\mathrm{PE}$, severe PE/E should receive thromboprophylaxis for four weeks after delivery (RCOG, NICE 2011), however, in this study no woman with PE received thromboprophylaxis, even for one day. This is of particular concern considering these women were attending a tertiary and teaching hospital, where high quality care is expected.

It is important to follow and monitor women with HDP to identify patterns of morbidities and any imminent complications (Slvaggi et al 1988). Although HDPs (except chronic hypertension) should typically resolve six to eight weeks after delivery, there is increasing evidence that hypertension does not resolve in all cases, remaining persistent and chronic in some (Garovic and August 2013, Craici et al 2008, McDonald et al 2008, Sibai et al 1986, Kaze et al 2014). In this study, hypertension persisted up to one year after delivery in a number of women (1 out of 4) with gestational hypertension, PE (1 out of 2), and severe PE/E (3 out of 14). Similarly, other aspects of metabolic functions also persisted in these women for one year, such as albuminuria (3.1\%), high serum creatinine (6.3\%), glucose intolerance, increased liver enzymes (Alanine and Aspartate transaminases), serum cholesterol, and triglycerides.

These findings indicate, as most guidelines specify, that all women with HDPs should be provided comprehensive medical reviews that include routine screening for metabolic syndrome, as well as referrals.

\section{Limitation}

The women who continued follow up care in this study are likely those with worse health outcomes, which compelled their continuation of care, than the other women with HDP recruited for the study who did not continue their care at $\mathrm{DMCH}$. This likelihood thus provides a study sample not fully representative of the results of HDP care and management at a tertiary care facility in Bangladesh. 


\section{Conclusion and Recommendations}

The following conclusions and recommendations-for health care providers, public health experts, policymakers, health administrators, and developmental partners in Bangladesh-emerged from this study of service provision to women with HDPs:

- Gaps in PNC are evident including clinical assessments, laboratory evaluations, patient counseling, and follow ups. Standard operating procedures (SOPS) for PNC should be developed including management of women with HDPs, and made widely available to obstetricians, nurses, and midwives who provide services to pregnant women.

- Challenges in women's postnatal health-seeking behaviors need to be addressed. Women with pregnancy and postnatal complications, as well as their families, require relevant and understandable information enabling their awareness and understanding of potential consequences for their future health, and thus the necessity of follow up consultations. Presently, counseling about potential future health complications is negligible. Health facilities and staff must find effective means of ensuring women's return to facilities for PNC and follow up, and increase efficiencies in facilities so service providers can provide effective counseling.

- Blood pressure is either not routinely measured, or measured and not documented; service providers treating pregnant women should be aware of the importance of routine BP measurement and monitoring of women, including after delivery, and its documentation. Routine monitoring and documentation should include urine albumin as well.

- All service providers should be aware that HDP does not necessarily resolve following delivery, and that all women with HDP must be monitored until resolution of their hypertension is confirmed and documented, to avoid any further complications. Screening for development of metabolic syndromes following PE-complicated pregnancies should be routine by service providers.

- Early detection of HDP and its careful management are essential, and it is recommended that all pregnant women are screened for PE after 20 weeks of pregnancy.

- Pre-term and LBW infant delivery were extremely common, and all women with HDP should be aware of the nearest hospital with neonatal support for delivery.

- Women with HDP were rushed or referred to DMCH from a number of districts surrounding Dhaka, which indicates inefficiencies and lack of capacities at lower levels as well as in many districts of the health system, for appropriately managing cases of HDP, and demands the improvement of their capacities. 


\section{References}

1. ACC/SCN. 2000. Fourth Report on the World Nutrition Situation. Geneva: ACC/SCN in collaboration with IFPRI.

2. Wilcox AJ. 2001. On the importance-and the unimportance-of birthweight. Int J Epidemiology 30: 1233-1241.

3. Arifeen SE. 1997. Birth weight, intrauterine growth retardation and prematurity: a prospective study of infant growth and survival in the slums of Dhaka. Bangladesh Doctor of Public Health dissertation, Johns Hopkins University, Baltimore MD.

4. Blencowe H, S Cousens, M Oestergaard, D Chou, AB Moller, R Narwal, A Adler, CV Garcia, S Rohde, L Say, JE Lawn. 2012. National, regional and worldwide estimates of preterm birth. Lancet 379(9832): 2162-2172.

5. Craici I, S Wagner, VD Garovic. 2008. Preeclampsia and future cardiovascular risk: formal risk factor or failed stress test? Therapeut Adv Cardio Disease 2(4): 249-259. PubMed 19124425.

6. Deruelle P, E Coudoux, A Ego, V Houfflin-Debarge, X Codaccioni, D Subtil. 2006. Risk factors for postpartum complications occurring after preeclampsia and HELLP syndrome. A study in 453 consecutive pregnancies. Eur J Obstet Gynecol Reprod Biol 125(1): 59-65.

7. Every Preemie Scale. 2018. Bangladesh: Profile of preterm and low birth weight prevention and care. Every Preemie scale. https://reliefweb.int/sites/reliefweb.int/files/resources/Bangladesh_4.pdf

8. Firoz T and T Melnik. 2011. Postpartum evaluation and long-term implications. Best Pract Res Clin Obstet Gyn 25(4): 549-556.

9. Kaze FF, FA Njukeng, AP Kengne, G Ashuntantang, R Mbu, MP Halle, T Asonganyi. 2014. Post-partum trend in blood pressure levels, renal function and proteinuria in women with severe preeclampsia and eclampsia in Sub-Saharan Africa: A 6-months cohort study. BMC Preg Childbirth 14: 134.

10. Gomathy E, L Akurati, K Radhika. 2018. Early onset and late onset preeclampsia-maternal and perinatal outcomes in a rural tertiary health center. Int J Repro Contracep Obstet Gyn 7(6): 22662269

11. Halim A, M Aminu, J Dewez, A Biswas, F Rahman, N Broek. 2018. Stillbirth surveillance and review in rural districts in Bangladesh. BMC Preg Childbirth 18. 10.1186/s12884-018-1866-2.

12. www.acog.org/Womens-Health/Preterm-Premature-Labor-and-Birth?IsMobileSet=false

13. Huppertz B. 2008. Placental origins of preeclampsia: challenging the current hypothesis. Hypertension 51(4): 970-975.

14. ICDDRB.2014. Press release. www.icddrb.org/dmdocuments/Press\%20release\%20preterm\%20birth\%20and\%20stillbirths\%20in\% 20Bangladesh.pdf

15. Payne J and J Cox. 2016. Pre-eclampsia and Eclampsia. https://patient.info/doctor/pre-eclampsiaand-eclampsia

16. Magee LA, P von Dadelszen, W Stones, M Mathai. 2016. The FIGO textbook of pregnancy hypertension: An Evidence-based guide to monitoring, prevention and management. ISBN 978-09927545-5-6. 
17. Lawn JE, H Blencowe, P Waiswa et al. 2016. Stillbirths: rates, risk factors, and acceleration towards 2030. Lancet 387: 587-603.

18. Madazli R, MA Yuksel, M Imamoglu, A Tuten, M Oncul et al. 2014. Comparison of clinical and perinatal outcomes in early- and late-onset preeclampsia. Arch Gynecol Obstet 290(1): 53-57.

19. McDonald SD, A Malinowski, Q Zhou, S Yusuf, PJ Devereaux. 2008. Cardiovascular sequelae of preeclampsia/eclampsia: a systematic review and meta-analyses. Am Heart J 156(5): 918-930. PubMed 19061708.

20. Melchiorre K, GR Sutherland, M Liberati, B Thilaganathan. 2011. Preeclampsia is associated with persistent postpartum cardiovascular impairment. Hypertension 58(4): 709-715.

21. National Institute for Health Care Excellence. 2013. Hypertension in Pregnancy: Quality Standard. www.nice.org.uk/guidance/qs35

22. National Institute for Health Care Excellence. 2013. Hypertension in Pregnancy: Quality Standard. www.nice.org.uk/guidance/qs35

23. National Institute of Population Research and Training (NIPORT), MEASURE Evaluation and ICDDR,B. 2010. Bangladesh Maternal Mortality and Health Care Survey. Dhaka: NIPORT, MEAUSRE Evaluation, ICDDR, B.

24. National Institute of Population Research and Training (NIPORT), Mitra and Associates and ICF. 2018. Bangladesh Demographic and Health Survey 2017-18: Key Indicators. Dhaka and Rockville, MD, USA: NIPORT, Mitra and Associates, ICF.

25. National Nutrition Services (NNS), Institute of Public Health Nutrition (IPHN) and Directorate General of Health Services. 2017. National Low Birth Weight Survey 2015. Dhaka: IPHN.

26. NICE. 2011. www.nice.org.uk/guidance/cg107/resources/hypertension-in-pregnancy-diagnosis-andmanagement-35109334009285

27. NICE. 2019. Hypertension in pregnancy: diagnosis and management. NICE: UK. www.nice.org.uk/guidance/ng133

28. Von Dadelszen P, LA Magee, JM Roberts. 2003. Subclassification of Preeclampsia. Hypertension Preg 22(2): 143-148.

29. HarmonQE , L Huang, DM Umbach, K Klungsøyr, SM Engel, P Magnus, R Skjærven, J Zhang, A Wilcox. 2015. Risk of Fetal Death with Preeclampsia. Am College Obst Gyn 125(3): 628-635.

30. Redman CW, ᄂ Beilin, J Bonnar. 1977. Treatment of hypertension in pregnancy with methyldopa: blood pressure control and side effects. Brit J Obst Gyn 84(6): 419-426.

31. Royal College of Obstetricians and Gynaecologists. 2015. Green-top Guideline 37a: Reducing the risk of thrombosis and embolism during pregnancy and the puerperium. www.rcog.org.uk/en/guidelinesresearch-services/guidelines/gtg37a

32. Royal College of Obstetricians and Gynaecologists. 2010. Hypertension in pregnancy: The management of hypertensive disorders during pregnancy. NICE Clinical guideline; revised reprint January 2011.

33. Sulistyowati S. 2017. Early and Late Onset Preeclampsia: What did really Matter? J Gyn Women's Health 5(4): 555670. DOI: 10.19080/JGWH.2017.05.555670 
34. Selvaggi L, G Loverro, FP Schena, C Manno, G Cagnazzo. 1988. Long term follow up of women with hypertension in pregnancy. Int J Gyn Obst 27(1): 45-49. PubMed 2905297.

35. Sibai BM, A el-Nazer, A Gonzalez-Ruiz. 1986. Severe preeclampsia-eclampsia in young primigravid women: Subsequent pregnancy outcome and remote prognosis. Am J Obst Gyn 155(5): 1011-1016. PubMed 3777042.

36. Abira T, KE Aghoa, FA Ogboa, GJ Stevensb, A Pagea, MA Hasnatc, MJ Dibleyd, C Raynes-Greenow. 2017. Predictors of stillbirths in Bangladesh: Evidence from the 2004-2014 nation-wide household surveys. Global Health Action 10: 1410048

37. Halbreich U. 2005. The association between pregnancy processes, preterm delivery, low birth weight, and postpartum depressions- The need for interdisciplinary integration. Am J Obst Gyn 193: 13121322.

38. Garovic VD and P August. 2013. Preeclampsia and the Future Risk of Hypertension: The Pregnant Evidence. Curr Hypertens Rep.

39. Wang H, ZA Bhutta, MM Coates et al. 2016. Global, regional, national, and selected subnational levels of still-births, neonatal, infant, and under-5 mortality,1980-2015: a systematic analysis for the global burden of disease study 2015. Lancet 388: 1725-1774.

40. Warren C, SMI Hossain, RA Nur, K Sultana, K Kirk, A Dempsey. 2015. Landscaping Report on preeclampsia and eclampsia in Bangladesh. Washington, DC: Population Council.

41. World Health Organization. 29th World Health Assembly (1976) agreed "Low birthweight is a weight at birth of less than 2,500 g (up to and including 2,499 g) irrespective of gestational age"

42. World Health Organization. 2018. WHO Recommendations on Antenatal Care for a Positive Pregnancy Experience: Summary. Geneva: WHO. License: CC BY-NC-SA 3.0 IGO. WHO/RHR/18.02.

43. World Health Organization. 2019. Disorders related to length of gestation and fetal growth (P05-P08). https://icd.who.int/browse10/2010/en\#/P07

44. World Health Organization. 2019. Preterm: Key facts. www.who.int/news-room/factsheets/detail/preterm-birth

45. World Health Organization. 2011. WHO Recommendation for Prevention and Treatment of Preeclampsia and Eclampsia. World Health Organization. ISBN 978-92-4-154833-5

46. Neggers YH.2018. Gestational Age and Pregnancy Outcomes. www.intechopen.com/books/pregnancy-and-birth-outcomes/gestational-age-and-pregnancyoutcomes 


\section{Appendix}

\section{Clinical and Laboratory Parameters Assessed}

Examples of prescribed ongoing care that were monitored and evaluated in this study:

- Measurement of BP daily for 2 days after birth for women with chronic and gestational hypertension and measurement of BP 4 times a day for first 2 days for women with PE.

- Measurement of BP, at least, once between day 3 and 5 after birth in women with all forms of hypertensive disorders in pregnancy.

- For women with PE, assess if they were asked about severe headache or epigastric pain any time BP was measured.

- If BP after birth were less than 150/100mmHg in women with HDPs.

- Continuation of anti-hypertensive treatment in appropriate cases.

- If women with gestational hypertension and pre-eclampsia who remained on anti-hypertensive treatment 2 weeks after discharge from hospital were offered a medical review

- If women with any form of HDPs were offered a medical review at between 6 to 8 weeks postpartum.

- If women with gestational hypertension and pre-eclampsia still required anti-hypertensive treatment after 6 to 8 weeks after birth

- If women with PE were transferred to community care (discharged) when there were no symptoms of PE, BP was less than $150 / 100 \mathrm{mmHg}$ and blood test results were stable or improving.

- If women who have suffered from pre-eclampsia had their platelets, transaminase, and serum creatinine measured 48 to 72 hours after delivery

- If women with PE had their urine protein estimated using urine dipsticks at 6 to 8 weeks after birth. If women with persistent proteinuria had a further review done at 3 months after birth to assess kidney function for possible referral for specialist kidney assessment.

- If women who have suffered from pre-eclampsia were advised to achieve and keep a Body Mass Index (BMI) within a health range $\left(18.5-24.9 \mathrm{~kg} / \mathrm{m}^{2}\right)$ before the next pregnancy.

Examples of medical complications that were monitored for, and evaluated in women who have suffered from HDPs included:

- Hypertension and its complications (stroke, cardiovascular disease)

- Presence or absence of modifiable cardiovascular risk factors such as high blood glucose, cholesterol and triglycerides.

- Long-term risk of end stage kidney disease (urea and creatinine)

- Increase risk or occurrence of thrombosis 